\title{
The Benefits of the Ka-Band as Evidenced from the SARAL/AltiKa Altimetric Mission: Scientific Applications
}

Jacques Verron ${ }^{1, *}$, Pascal Bonnefond ${ }^{2}$, Lofti Aouf ${ }^{3}$, Florence Birol ${ }^{4}$, Suchandra A. Bhowmick ${ }^{5}$, Stéphane Calmant ${ }^{4}$, Taina Conchy ${ }^{6}$, Jean-François Crétaux ${ }^{4}$, Gérald Dibarboure ${ }^{7}$, A. K. Dubey ${ }^{5}$, Yannice Faugère ${ }^{8}$, Kevin Guerreiro ${ }^{4}$, P. K. Gupta ${ }^{5}$, Mathieu Hamon ${ }^{9}$, Fatma Jebri ${ }^{4}$ (D),

Raj Kumar ${ }^{5}$, Rosemary Morrow ${ }^{4}$ (i) , Ananda Pascual ${ }^{10}$, Marie-Isabelle Pujol ${ }^{8}$, Elisabeth Rémy ${ }^{9}$, Frédérique Rémy ${ }^{4}$, Walter H. F. Smith ${ }^{11}$ (iD) , Jean Tournadre ${ }^{12}$ and Oscar Vergara ${ }^{4,8}$

1 Institut des Géosciences de l'Environnement (IGE), CNRS, 38041 Grenoble, France

2 SYRTE, Observatoire de Paris, PSL Research University, CNRS, Sorbonne Universités, UPMC Univ. Paris 06, LNE, 75014 Paris, France; pascal.bonnefond@obspm.fr

3 Météo-France, 31057 Toulouse, France; lotfi.aouf@meteo.fr

4 Laboratoire d'Etudes en Géophysique et Océanographie Spatiales (LEGOS), 31400 Toulouse, France; florence.birol@legos.obs-mip.fr (F.B.); stephane.calmant@ird.fr (S.C.);

jean-francois.cretaux@legos.obs-mip.fr (J.-F.C.); guerrei@legos.obs-mip.fr (K.G.);

fatma.jebry@gmail.com (F.J.); rosemary.morrow@legos.obs-mip.fr (R.M.); remy.omp@free.fr (F.R.); oscar.vergara@legos.obs-mip.fr (O.V.)

5 Space Applications Centre (ISRO), Ahmedabad 380015, India; suchandra@sac.isro.gov.in (S.A.B.); a_dubey@sac.isro.gov.in (A.K.D.); pkgupta@sac.isro.gov.in (P.K.G.); rajkumar_62@rediffmail.com (R.K.)

6 Universidade do Estado de Amazonas, Manaus 69020, Brazil; taina.conchy@inpa.gov.br

7 Centre National d'Etudes Spatiales (CNES), 31400 Toulouse, France; gerald.dibarboure@cnes.fr

8 Collecte Localisation Satellites (CLS), 31520 Ramonville Saint-Agne, France; yannice.faugere@cls.fr (Y.F.); mpujol@cls.fr (M.-I.P.)

9 Mercator Océan, 31520 Ramonville Saint-Agne, France; mathieu.hamon@mercator-ocean.fr (M.H.); elisabeth.remy@mercator-ocean.fr (E.R.)

10 Institut Mediterrani d'Estudis Avançats (IMEDEA) (CSIC-UIB), 07190 Esporles, Illes Balears, Spain; ananda.pascual@imedea.uib-csic.es

11 Laboratory for Satellite Altimetry, NOAA, College Park, MD 20740-3818, USA; walter.hf.smith@noaa.gov

12 Laboratoire d'Océanographie Physique et Spatiale (LOPS), 29280 Plouzané, France; jean.tournadre@ifremer.fr

* Correspondence: jacques.verron@univ-grenoble-alpes.fr

Received: 29 November 2017; Accepted: 19 January 2018; Published: 24 January 2018

\begin{abstract}
The India-France SARAL/AltiKa mission is the first Ka-band altimetric mission dedicated primarily to oceanography. The mission objectives were firstly the observation of the oceanic mesoscales but also global and regional sea level monitoring, including the coastal zone, data assimilation, and operational oceanography. SARAL/AltiKa proved also to be a great opportunity for inland waters applications, for observing ice sheet or icebergs, as well as for geodetic investigations. The mission ended its nominal phase after three years in orbit and began a new phase (drifting orbit) in July 2016. The objective of this paper is to highlight some of the most remarkable achievements of the SARAL/AltiKa mission in terms of scientific applications. Compared to the standard Ku-band altimetry measurements, the Ka-band provides substantial improvements in terms of spatial resolution and data accuracy. We show here that this leads to remarkable advances in terms of observation of the mesoscale and coastal ocean, waves, river water levels, ice sheets, icebergs, fine scale bathymetry features as well as for the many related applications.
\end{abstract}

Keywords: altimetry; Ka-band; oceanography; hydrology; ice; geodesy 


\section{Introduction}

The India-France SARAL/AltiKa mission is the first Ka-band altimetric mission dedicated to oceanography. SARAL was launched on 25 February 2013. Today, the SARAL/AltiKa mission is in its fifth year, which means that it has reached its design life. The mission will continue as long as the satellite and the ground segment continue to operate. The lifetime requirement of the AltiKa payload was just three years, which has clearly been exceeded. The instruments are still in perfect conditions.

The SARAL satellite is composed of a spacecraft bus developed by the Indian Space Agency (ISRO), and a payload developed by the French Space Agency (CNES). As its full name (SARAL stands for "Satellite with ARgos and ALtiKa") indicates, two missions are onboard the SARAL satellite: The AltiKa altimeter component and ARGOS-3, the new generation of ARGOS instrument. For the scientific applications discussed in this paper, we focus on AltiKa. The altimeter payload is composed of the AltiKa altimeter-radiometer in Ka-band, a Doris system for precise orbit determination (POD), and a Laser Retro-reflector Array instrument used for precise calibration of other POD instruments. AltiKa is a nadir-looking altimeter in line with Poseidon-3 on-board Jason-3 and other existing altimeters, but operates in a single frequency band: the Ka-band. It is the reduced ionosphere effects in Ka-band that makes it possible to use a mono-frequency altimeter. The altimeter shares the antenna with a bi-frequency radiometer required to correct the altimeter range for the wet troposphere path delay. The SARAL satellite orbit is almost polar, sunsynchronous and with a 35-day repeat cycle. This is the same orbit as Envisat with the initial motivation to continue the time series and to benefit from the existing mean sea surface. Since March 2015, technical issues have been encountered on the reaction wheels and this has led to the decision of relaxing the orbit. Then, after 4 July 2016, SARAL/AltiKa left its repetitive orbit by beginning a new phase named "SARAL Drifting Phase" (SARAL-DP). The data processing as well as data latency have not been changed. From this date, SARAL satellite does fly free of station keeping maneuvers which means there is a drift between successive ground tracks which are no more repetitive. The altimetry payload is operated nominally on the drifting orbit. The cycle duration of 35 days is no longer kept but the orbit has been chosen to preserve anyway subcycles within the range of 15 to 17 days quite relevant for mesoscale sampling.

For further information on SARAL/AltiKa, one can refer to introductory papers [1,2] and more widely to the Special Issue of Marine Geodesy dedicated to this satellite [3].

Since the beginning of the SARAL/AltiKa mission, performances proved to be compliant with nominal specifications with an overall observed performance for the sea surface height (SSH) RMS of $3.4 \mathrm{~cm}$, lower than the mission requirement of $4 \mathrm{~cm}$ (see also [4]). In general, SARAL/AltiKa performances appear to be quite similar, and often better, than the Ku-band reference altimetric satellites such as Jason-2. Before launch, concerns were raised about the sensitivity of the Ka-band to rain events, leading to missing and invalid measurements. However, in practice, the SARAL/AltiKa data return is remarkably high with few missing data. Over the ocean, the data coverage is greater than $99.5 \%$, which, once again, exceeds the mission requirements. SSH differences at crossovers is the main metric to assess the overall performance of satellite altimetry missions. In this regard, the results obtained from the SARAL/AltiKa mission are of the same order, or even better, as those obtained for Jason-2 mission. The same result is obtained for the sea level anomalies (SLA): SARAL/AltiKa data quality is as good (or even slightly better) as Jason-2. Another key factor for altimetry applications is the spectral content of the data. AltiKa altimeter provides a signal-to-noise ratio which has never been obtained before. Compared to Jason-2 and CryoSat-2 (SAR mode) data, the spectral content of SARAL/AltiKa observations is largely improved for all wavelengths below $70 \mathrm{~km}$. This is explained by the much lower white noise, due to the excellent Ka-band retracking performances and also to the $40 \mathrm{~Hz}$ measurement rate (higher than the standard $20 \mathrm{~Hz}$ on Jason-class and CryoSat-2 missions). In conclusion, the mission performances widely confirm the nominal expectations in terms of accuracy, data quality and data availability.

The mission objectives are the observation of the oceanic mesoscale dynamics, including the coastal zone, but also the global and regional sea level monitoring, data assimilation and operational 
oceanography. It also includes the monitoring of the level of the main continental water bodies (lakes, rivers, enclosed seas), of large-scale sea level variations, the observation of polar oceans (as a result of the high inclination of its orbit), the analysis and forecast of wave and wind fields, the study of continental ice and sea ice, the access to low rains climatology and the marine biogeochemistry (mostly through improved mesoscale access).

Beyond the excellent quality of SARAL/AltiKa measurements, there are some specificities that emerge from the Ka-band altimetry. Different scientific results illustrate these specificities. The objectives of this paper are to give precise evidence of the main features of the SARAL/AltiKa that are associated with the Ka-band. In a companion paper [4], we looked at the quality assessment and specificities of AltiKa data. In the present paper, we focus more on the scientific aspects. Rather naturally, the paper is organized following the main scientific applications of SARAL/AltiKa: oceanography, hydrology, ice and geodesy. Some examples are given to illustrate some salient features of today's SARAL/AltiKa data with regard to standard altimetry: data accuracy allowing significant advances in the field of ocean mesoscale studies and for operational applications, in coastal areas, over ice, for inland waters and finally for geodesy.

\section{The Ocean}

As previously mentioned, SARAL/AltiKa's main scientific objective is to provide data products to the oceanographic community with the aim to improve our knowledge of the ocean mesoscale variability, mainly associated to eddies, meandering currents, fronts, filaments and squirts. The mesoscale variability refers to ocean signals with space scales of $50 \mathrm{~km}$ to $500 \mathrm{~km}$ and time scales from a few days to a few months. The associated kinetic energy is at least an order of magnitude larger than that of the mean circulation. It is now well recognized that the mesoscale processes are a key component of the ocean circulation, shaping the mean currents, controlling the exchanges with the atmosphere and the marine biogeochemistry, and clearly playing a major role in the way the ocean participate to the climatic system.

The sea level measurements of SARAL/AltiKa are used in theoretical and observational studies, modelling, data assimilation, etc. Because mesoscale and fine scale dynamical processes are particularly important in the coastal ocean, the observational capabilities of SARAL/AltiKa are also expected to bring an important contribution to the study of coastal dynamics. It is particularly important for many downstream applications including operational oceanography which is fed by a large amounts of in-situ and space-based data. Similar to previous altimeters, SARAL/AltiKa not only provide sea level measurements, but also ocean wave observations through the significant wave height $(\mathrm{SWH})$ parameter. Ocean waves play a key role in ocean-atmosphere exchanges at the sea interface. It is essential to have the most accurate knowledge possible of the sea state for climate and meteorological studies.

\subsection{Observability of the Fine-Scale Ocean Dynamics}

Technological advances in all of the recent satellite altimeter missions have improved their signal-to-noise ratio, allowing us to observe finer-scale ocean processes with along-track altimeter data. By calculating wavenumber spectra from along-track SSH anomalies from the recent missions, we have been able to estimate the background noise levels of each mission, and the corresponding observable ocean scales, where the signal-to-noise is greater than 1 . This statistical estimate of the altimetric noise and the observable scales has been performed over the global oceans using Jason-2 (Ku-band), SARAL/AltiKa (Ka-band) and CryoSat-2 in low-resolution mode (LRM) by [5], and from Jason-2, SARAL/AltiKa and Sentinel-3 in Synthetic Aperture Radar (SAR) mode by [6]. Regional analyses have also been performed over the western Mediterranean Sea by [7] using Jason-2, SARAL/AltiKa and CryoSat-2 SAR mode.

An example of the globally-averaged sea level anomaly (SLA) wavenumber spectra are shown in Figure 1 from three missions with different technologies : Jason-2, SARAL/AltiKa and Sentinel-3 in SAR mode [6]. All missions observe similar SLA spectral levels at scales larger than $100 \mathrm{~km}$ wavelength. 
At shorter scales, the SLA spectra are dominated by the error level of each missions. Jason-2 has a higher mean noise level with a strong "bump" from 10 to $50 \mathrm{~km}$ wavelength due to surface roughness inhomogeneities within its relatively large footprint, mainly from surface waves. SARAL/AltiKa has the smallest noise at very short scales, but is also affected by the spectral "bump" at scales of 3-20 km wavelength (note that standard data processing is applied here; with more sophisticated treatment, these spectral bumps can be reduced without changing the hierarchy of satellite data quality for small ocean scales [4]). Sentinel-3 in SAR mode has a significant reduction in the spectral bump and the smallest error level at $10 \mathrm{~km}$ wavelength, with a different "red" noise spectrum. Both SARAL/ AltiKa and Sentinel-3 SAR data observe similar SSH variability down to scales of $40 \mathrm{~km}$ wavelength.

Each altimeter's error field shows distinct seasonal and geographical variations, with higher noise in winter due to the rougher sea state [5]. We have recently extended this work to analyse SARAL/AltiKa over a longer three-year period when both missions were on a repeat groundtrack with low mean sea surface errors. SARAL/AltiKa has relatively low $1 \mathrm{~Hz}$ noise, but still exhibits strong seasonal variations in noise (Figure 2). The $1 \mathrm{~Hz}$ noise is higher in each hemisphere in the region of highest winter waves, but also increases in the boundary currents due to wave-current interactions, and in the tropics due to rain cells or calm water patches, all leading to inhomogeneities within the footprint. In the western Mediterranean Sea, similar seasonal patterns were found [7] (not shown).

These statistical noise levels impact on the ocean scales we can observe. In the global ocean, SARAL/AltiKa can observe scales of $30 \mathrm{~km}$ in the strong boundary currents and the tropics, reaching $70-80 \mathrm{~km}$ in the quieter eastern basin where the signal-to-noise ratio is low [5]. Conversely, the higher noise of Jason-2 limits the observation scales: we can only resolve processes of $40-50 \mathrm{~km}$ in the western boundary currents, and $80-100 \mathrm{~km}$ in the eastern basins. Note that these spectral wavelength limits correspond to individual feature diameters of half that size, i.e., with SARAL/AltiKa we can detect strong western boundary eddies down to $15 \mathrm{~km}$ diameter (30 km in wavelength). In the Mediterranean Sea, where the Rossby radius is small, the difference between SARAL/AltiKa and Jason-class altimeters is also striking [7]. In winter, when the mixed layers are deepest and the submesoscale is energetic, all of the altimeter missions can observe wavelengths down to 40-50 km. In summer, when the submesoscales are weaker, SARAL/AltiKa with its lower noise can detect ocean scales down to $35 \mathrm{~km}$ wavelength, whereas the higher noise from Jason-2 blocks the observation of scales less than 50-55 km wavelength.

The noise levels impacting on the observation of fine-scale dynamics depend on many factors, including surface roughness from different wind-wave-swell conditions, impact from rain or other geophysical corrections [5,8], and errors in the geoid or mean sea surface (MSS). Even with the new generation of MSS products, when a satellite drifts off the long-term mean repeat track with its accurate MSS, the error in SLA increases. Figure 3 shows the evolution of the SLA standard deviation, calculated with respect to different MSS products, during a period when the SARAL/AltiKa mission drifted from its long-term mean groundtrack (cycles 23-25, marked in gray, from [9]). The data have been filtered to retain only short wavelengths less than $200 \mathrm{~km}$, which have the largest gridded MSS errors. The standard deviation for Jason-2 (in black) is calculated from the precise alongtrack MSS, whereas for SARAL/AltiKa it is calculated with respect to different MSS models. Figure 3 highlights the lower standard deviation of SARAL/AltiKa SLA compared to Jason, but even when the recent MSS models are used with the most geodetic data included (MSS CNES_CLS15), the error increases during the drifting orbit phase. Work is in progress to better understand and estimate these different geophysical signals, in order to reduce their effects on the SLA noise.

Although SARAL/AltiKa and Jason-2 show a similar pattern in seasonal and geographical variations of their noise, these studies quantify that the low background noise levels of SARAL/AltiKa enable this mission to make the most precise estimates of the fine-scale ocean dynamics, in the open ocean and regional and coastal seas. This is encouraging for further studies with SARAL/AltiKa , but also in the preparation for the future Ka-band wide-swath altimeter mission from NASA/CNES, 
the Surface Water Ocean Topography (SWOT) mission, whose lower noise should enable us to observed even smaller ocean scales.

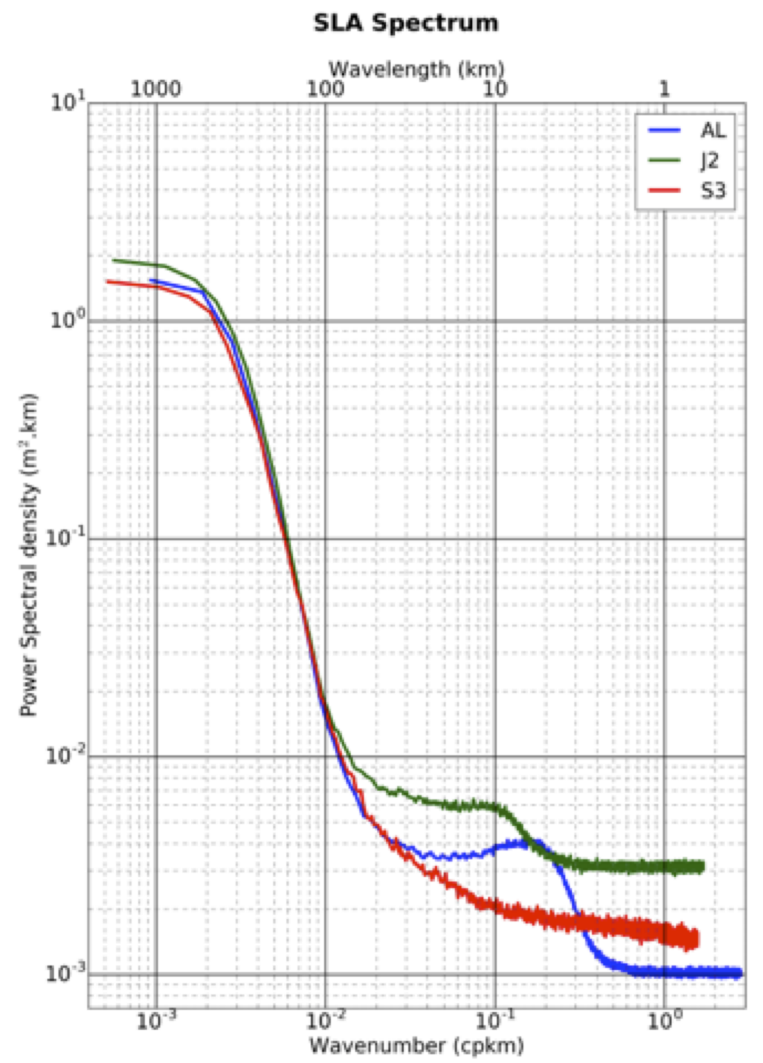

Figure 1. Globally-averaged wavenumber spectra of SSH anomalies (in $\mathrm{m}^{2} / \mathrm{cpkm}$ ) from the highest resolution along-track data for three different missions: Jason-2 $20 \mathrm{~Hz}$ (J2 in green); SARAL/AltiKa $40 \mathrm{~Hz}$ (AL in blue); and Sentinel-3 $20 \mathrm{~Hz}$ SAR (S3 in red). The spectral "bump" in Jason-2 and SARAL/AltiKa data is due to surface roughness inhomogeneities within the footprint, mainly from surface waves.

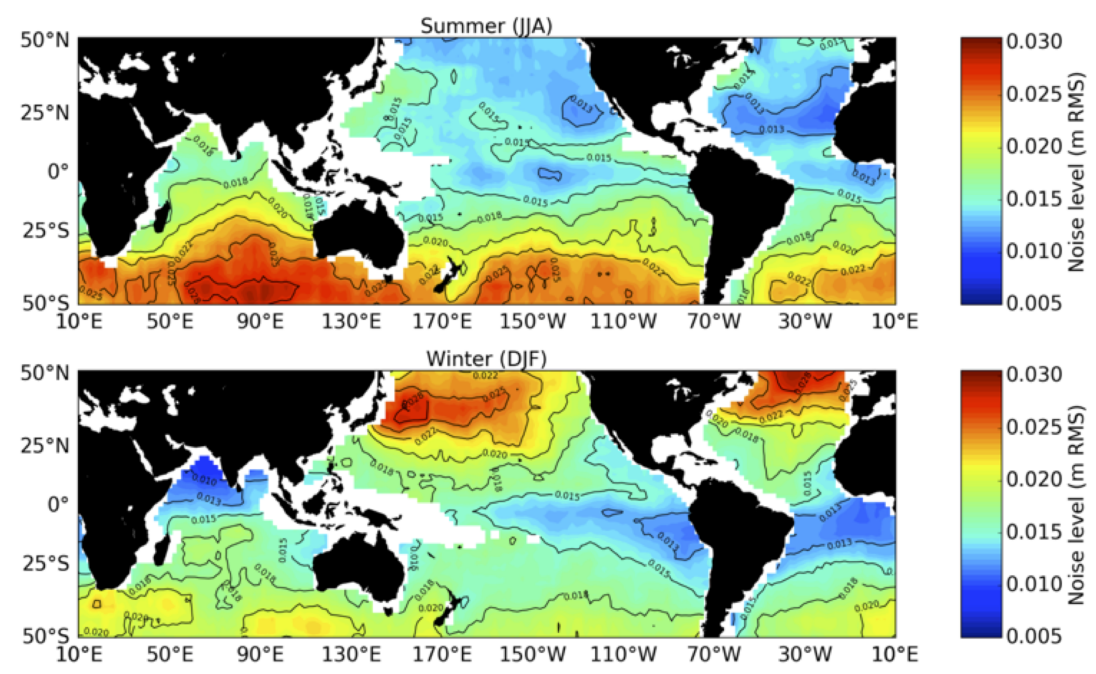

Figure 2. Geographical distribution of the $1 \mathrm{~Hz}$ noise level over the global oceans in: (upper panel) June-August; and (lower panel) December-February. The noise is estimated from wavenumber spectra averaged over $15^{\circ} \times 15^{\circ}$ boxes, as a constant value fit over the wavelengths $14-30 \mathrm{~km}$. 


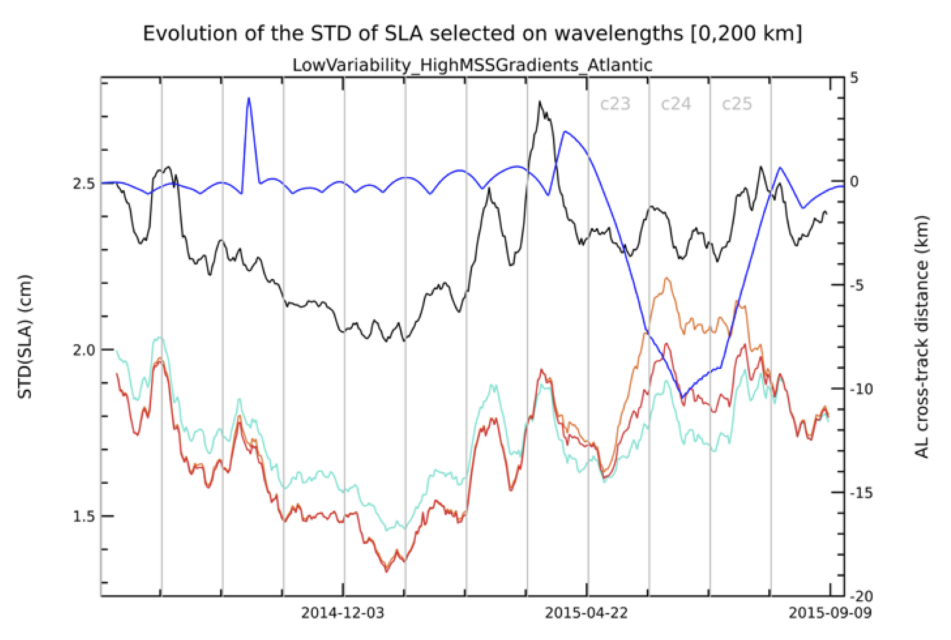

Figure 3. Temporal evolution of the standard deviation of the SLA, along Jason-2 tracks (calculated with respect to its alongtrack precise MSS in black) and along SARAL/AltiKa tracks (calculated with respect to different gridded MSS products: MSS CNES_CLS15 (in red), CNES_CLS11 (in orange) and DTU15 (in cyan). The SLA was high-pass filtered to keep only wavelengths shorter than $200 \mathrm{~km}$. Statistics are computed over a low variability and intense bathymetric gradients region in the northeast Atlantic $\left[20^{\circ} \mathrm{S}, 0^{\circ} \mathrm{N} ; 30^{\circ} \mathrm{W}, 0^{\circ} \mathrm{E}\right]$. The blue line shows the cross-track distance (in $\mathrm{km}$; right axis) of the SARAL/AltiKa tracks compared to their long-term repeat groundtrack; this distance increases sharply during cycles C23, C24, and C25, marked in gray from 22 April 2015 onwards.

\subsection{Observability of the Coastal Ocean Dynamics}

Satellite altimetry represents a mature technology in the open ocean but its exploitation remains an issue in the coastal ocean for different reasons. Land contamination in the altimeter footprint lead to a signal which is much more complex to analyze than offshore and often lead to the rejection of the altimetry measurements during the standard processing step. Geophysical corrections are significantly less accurate in the coastal area. The radiometer measurements used to derive the wet-troposphere correction becomes perturbed by land $25-50 \mathrm{~km}$ from the coast (depending on the instrument). The coastal ocean dynamics have also shorter space and time scales than the scales of open ocean dynamics which are mostly resolved by altimetry. Consequently, coastal altimetry data are largely discarded in standard products distributed to users and then largely unexploited. However, having as many accurate observations of the coastal ocean as possible is crucial for improving our understanding and monitoring of physical ocean processes that impact a wide range of applications (coastal area management, risk prevention, fisheries, marine safety and shipping, pollution, etc). In the context of climate change, we need to observe and understand how the coastal sea level variations, in particular extreme events such as storm surges, but also those associated to much lower time scales, impact the coastal morphology (via erosion). In the last years, a lot of efforts have been dedicated in the coastal altimetry community in order to extend the observational capabilities of altimeters always closer to the coastline (e.g., http:/ / www.coastalal.eu). The launch of the SARAL/AltiKa altimetry mission, with an instrument able to provide accurate sea level measurements at a higher spatial resolution and closer to the coastline, is a major step forward.

\subsubsection{Observability of the Coastal OceanDynamics in the Central Mediterranean Sea}

In a first illustration of the benefits of SARAL/AltiKa, we analyse if the improved altimetric capabilities of SARAL/AltiKa that has been shown in different studies (e.g., [5,7]) can lead to the detection of finer ocean scales in the Central Mediterranean Sea. In this area, the observation of the different current branches by altimetry is particularly challenging due to their short width and high space-time variability [10]. Figure 4 (left) shows an example of the wavenumber spectra calculated over 
the study area from both Jason-2 and SARAL/AltiKa along-track SSH. This very local result obtained from a data set including coastal altimetry observations (unlike the studies mentioned above) confirms what has already been obtained elsewhere. At wavelengths $>80 \mathrm{~km}$, SARAL/AltiKa and Jason-2 SLA spectra are very similar. Below $80 \mathrm{~km}$, the spectral energy of SARAL/AltiKa decreases significantly more than for Jason-2. Using the same spectral analysis approach than [5,7] for different altimetry tracks crossing the Central Mediterranean Sea, we deduce that the mesoscale observational limit occurs around $46 \mathrm{~km}$ wavelength (for a 12-35 km estimated noise level) for Jason-2 and around $21 \mathrm{~km}$ wavelengths (for a 12-18 km estimated noise level) for SARAL/AltiKa. These numbers are slightly lower than the results obtained by [7] further north in the northwestern Mediterranean Sea, confirming the strong dependency of the observational capability of altimetry missions to the level of mesoscale energy. These results have been used to define for both altimetry missions the optimal spatial filtering of alongtrack SLA: a low-pass Lanczos filter with a 21/45 km cutoff frequency for SARAL/Jason-2.
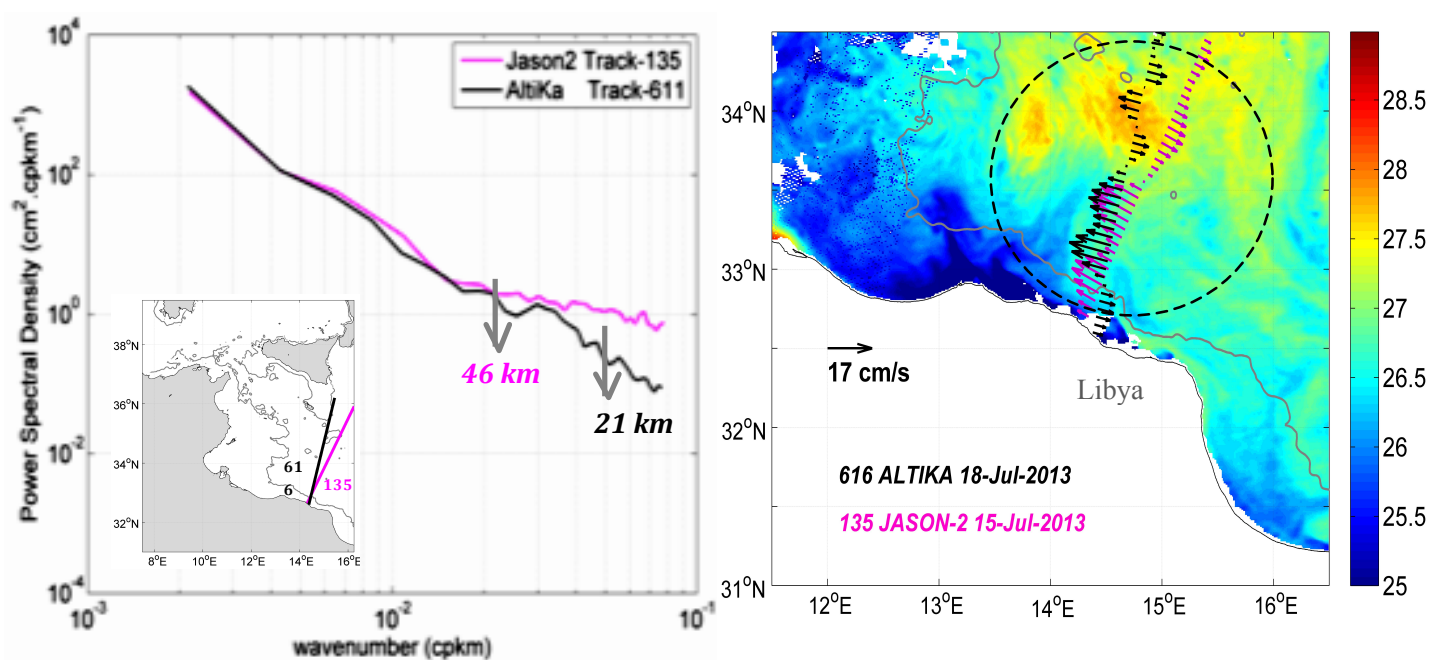

Figure 4. (Left) Wavenumber spectra from SSH observed in the Central Mediterranean Sea along the track 616 of SARAL/AltiKa (black) and along the track 135 of Jason-2 (pink); and (Right) comparisons of SST (in ${ }^{\circ} \mathrm{C}$ ) with SARAL/AltiKa track 616 (black) and Jason-2 track 135 (pink) crosstrack velocities over the Tunisia-Lybian shelf for 18 July 2013. The SST pattern is derived from CMEMS products with $1 / 16^{\circ}$ resolution. The $200 \mathrm{~m}$ isobath (in grey) is derived from the ETOPO2v1 database. The black dashed circle indicates the location of the Sidra Gyre.

To illustrate the impact of the improved observational capability of SARAL/AltiKa in terms of ocean circulation captured, the crosstrack absolute geostrophic velocities are computed from both the filtered SARAL/AltiKa and Jason-2 sea level data, adding the mean dynamic topography provided by AVISO to the SLA. They have then been compared to the information provided by high resolution Level 3 sea surface temperature (SST) 2D fields. Figure 4 (right) illustrates an example of this qualitative analysis. This zoom on the Tunisian-Libyan shelf for 18 July 2013 shows the presence of warmer waters north of the Lybian continental margin. From [10,11], it corresponds to the anticyclonic Sidra Gyre (black dashed circle), permanent feature of the regional circulation which advects warm and salty Ionian water through a surface current flowing northwestward offshore Libya. This feature is observed in both SARAL/AltiKa and Jason-2 current patterns but finer scales are derived from SARAL/AltiKa data and the undulations in the corresponding higher resolution surface currents perfectly correspond to the variations in the SST field.

Near the coast, on the Lybian shelf, the information provided by Jason-2 and SARAL/AltiKa diverge. In Jason-2, the surface currents still flows northwestward, while a southeastward current vein 
is observed in SARAL/AltiKa. For this date, SST data indicate the presence of colder waters flowing along the Libyan coast. They correspond to the AtlanticWaters advected Southeastward by the narrow Atlantic Lybian Current along the Tunisian-Libyan continental slope (see [10,11]). This very coastal current vein is captured by SARAL/AltiKa observations but not by Jason-2. This example shows how the better mesoscale resolution of SARAL/AltiKa allow to observe new signals, even near the coast, and then help to understand the fine-scale ocean dynamics.

\subsubsection{SARAL-AltiKa Capabilities to Detect Coastal Currents: Comparisons With Jason-2 and HF Radar Data}

In a second example, we refer to measurements of the surface velocity from radar. Among the various alternative sensors available, coastal High Frequency Radar is unique as it provides synoptic, high frequency and high resolution data at the boundary between the ocean and the atmosphere [12]. Here, we build up on a previous study [13] aimed at evaluating SARAL/AltiKa data in the coastal ocean (7-60 km from the shore). In that study, the altimeter performance was evaluated in the Ibiza Channel (Western Mediterranean) by estimating geostrophic currents and comparing them to high frequency $(\mathrm{HF})$ radar surface velocities. Results showed that SARAL/AltiKa data were retrieved at a distance of only $7 \mathrm{~km}$ from the coast. The derived velocities revealed coherent mesoscale features with high temporal variability among the different cycles and with general reasonable agreement with HF radar fields (correlations of 0.54 , which are significant at the $95 \%$ confidence level). In the present example, we also perform the comparison with Jason-2, whose track 187 crosses SARAL/AltiKa track 16 in the vicinity of Ibiza Island (Figure 5). The period of study is 18 April 2013 to 8 May 2014. The same processing as in [13] is applied for HF radar and as well as for both SARAL/AltiKa and Jason-2 missions. Surface geostrophic velocities from altimetry are computed by finite differences applied to the Absolute Dynamic Topography (ADT), which is obtained by adding SLA and the SMDT-MED2014 Mean Dynamic Topography [14]).

We then compare the mean across-track velocities for every satellite cycle with the equivalent interpolated HF radar vectors (3 days averages). As expected (Figure $5 c, d$ ) and due to the different repetitive cycle of each mission, the number of cycles available during the study period for SARAL/AltiKa is a factor of 3.5 less than for Jason-2. SARAL and HF radar mean velocities reveal a consistent pattern raising to positive significant correlations of 0.74 (Table 1 ). On the contrary, in the section sampled by Jason-2 (which is less than $10 \mathrm{~km}$ apart from SARAL/AltiKa ), the time series are much noisier (both for radar and satellite) without a clear seasonal pattern. This translates in an insignificant correlation between Jason-2 and HF radar observations. However, RMS differences between satellite and HF radar velocities are of the same order $(9 \mathrm{~cm} / \mathrm{s})$ for both missions. A more in depth investigation is needed to interpret and understand these results. Further works should span over a longer time period and interpret and extend the spatial coverage to an array of HF radars, taking advantage of the recent initiative to establish a pan-European HF radar network [12].

Table 1. Statistics of the comparisons between HF radar and altimetric across-track geostrophic velocities over the period comprised between 18 April 2013 and 8 May 2014. Twelve measurements are used for SARAL/AltiKa (repeat cycle of 35 days) and 36 measurements are considered for Jason-2 (repeat cycle of 9.9156 days; note that several cycles were missing for Jason-2).

\begin{tabular}{lcc}
\hline & SARAL-AltiKa & Jason-2 \\
\hline Correlation & 0.7382 & -0.2481 \\
Std (HF radar) (m/s) & 0.0695 & 0.0518 \\
Std (satellite) (m/s) & 0.1055 & 0.0622 \\
Rms Diff (HF radar - & 0.0942 & 0.0969 \\
satellite)(m/s) & & \\
\hline
\end{tabular}



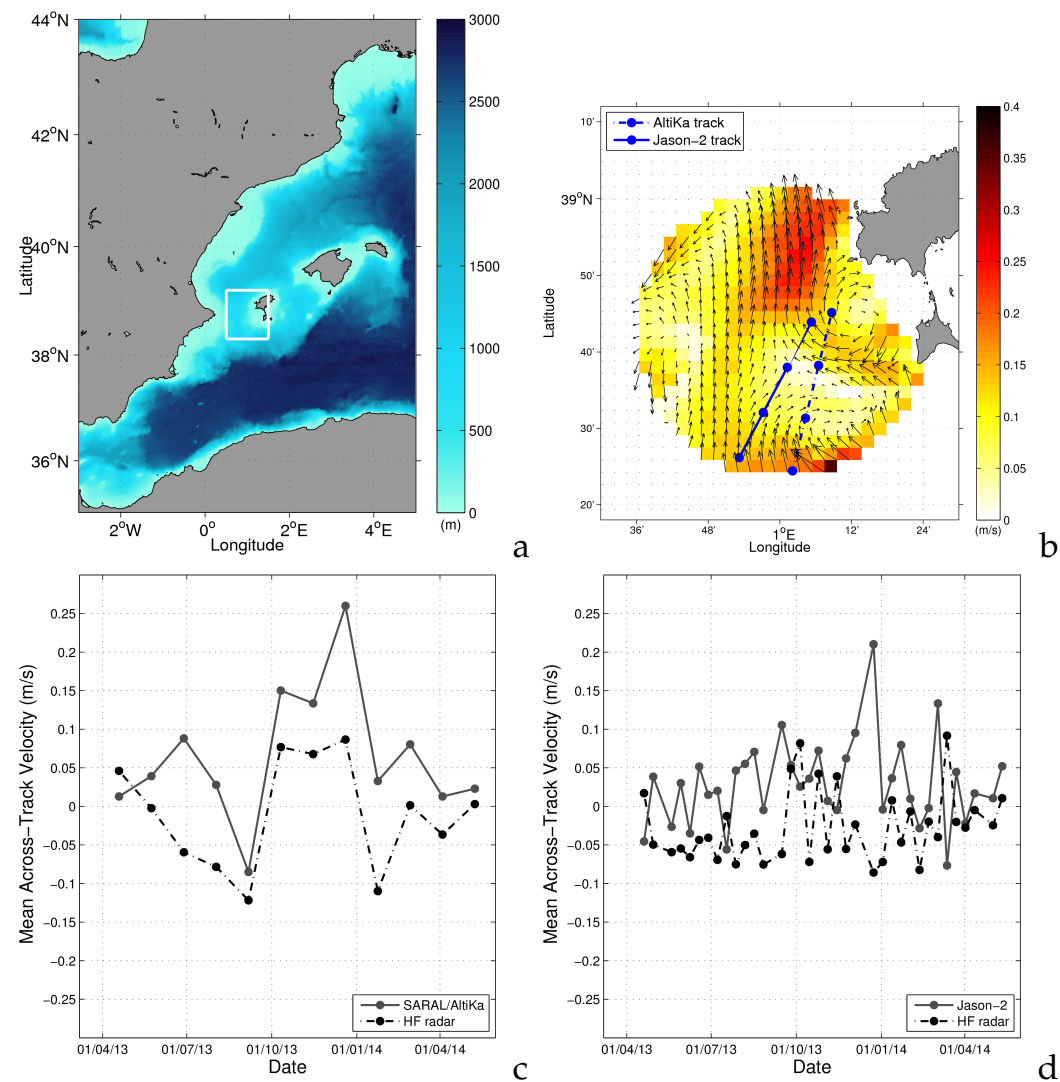

Figure 5. (a) Area of study in the Western Mediterranean. Colour contours represent bottom bathymetry and the white box corresponds to the area covered by the Ibiza HF radar shown in (b). (b) Coverage of SOCIB HF radar in the Ibiza Channel. The vectors correspond to surface velocities derived from HF radar (17 April 2013) field (three-day average). The colours are currents magnitude (in m/s). SARAL/AltiKa track 16 and Jason-2 track 187 are overlaid. The dots correspond to the position of the geostrophic velocity vectors derived from the altimeter missions. Note that the along-track delayed-time data provided at CMEMS is filtered with a $42 \mathrm{~km}$ filter and sub-sampled every $14 \mathrm{~km}$ (see details in [13]). (c) Comparison of the temporal variability of SARAL/AltiKa and HF radar mean cross-track velocity. X-axis is the number of cycles. (d) The same as (c) but for Jason-2.

\subsection{SARAL/AltiK a Data Into Operational Systems}

Altimetry is one of the most important data sources for assimilation into operational models. It provides global, real time, all-weather SSH measurements with high space and time resolution. Sea level is directly related to ocean circulation through the geostrophic approximation but sea level is also an integral of the ocean interior and is a strong constraint for inferring the $4 \mathrm{D}$ ocean circulation through data assimilation. Altimeters also measure $\mathrm{SWH}$, which is essential for operational wave forecasting. High resolution from multiple altimeters is required to adequately represent ocean eddies and associated currents in models. Only altimetry can constrain the 4D mesoscale circulation in ocean models which is required for most operational oceanography applications.

There are very strong links between satellite oceanography and operational oceanography. The development of operational oceanography has been mainly driven by the development of satellite oceanography capabilities. The ability to observe the global ocean in near real time at high space and time resolution is indeed a prerequisite to the development of global operational oceanography and its applications. The first ocean parameter to be globally monitored from space was the SST on board meteorological satellites in the late 1970s. It is, however, the advent of satellite altimetry in the late 1980s that led the development of ocean data assimilation and global operational oceanography. 
The satellite altimetry community was also keen to develop further the use of altimetry and this required an integrated approach merging satellite and in-situ observations with models.

\subsubsection{SARAL/AltiK a Major Contributor to DUACS/CMEMS Multi-Mission Seal Level Products}

For more than four years, SARAL/Altika products over ocean have been an important source of information for operational oceanography systems both in terms of assimilation and validation. Thanks to the efficiency of CNES and ISRO, the DUACS Sea Level system [15] was able to ingest SARAL/AltiKa data from 1 July 2013 onward in NRT, and merged them with the other flying satellites Jason-2, CryoSat-2 and HY-2A, to produce homogeneous set of Level 3 (along-track cross-calibrated SLA) and Level 4 (L4) products (multiple sensors merged as maps or time series).

Figure 6 shows the relative contribution of each mission in the multi-altimeter L4 products. This contribution (in \%) is derived from a degrees of freedom of signal analysis described by [8]. During the first month, SARAL/AltiKa strongly contributes up to $40 \%$, allowing us to mitigate the loss of Jason- 1 few months earlier. Its contribution decreases by $\sim 10 \%$ after the integration of HY-2A but rose again after HY-2A is removed of the system due to quality issues. During its whole repetitive period, SARAL/AltiKa was the second contributor, just after Jason-2 reference mission of the DUACS system because of an unexpected availability over the data over ocean as well as a very good timeliness of the OGDR and IGDR. With such a timeliness, and taking advantage of the "on the fly" DUACS system improvement implemented in February 2013, operational oceanography centres have been able since the beginning of the mission to access to homogeneous and cross calibrated DUACS SARAL/AltiKa products within a few hours. Another reason of this high contribution is the low noise level of SARAL/AltiKa enabled by its new Ka-band technology associated with its small footprint. Indeed, the energy removed from SARAL/AltiKa data by the DUACS filtering process is lower compared to what is removed from Jason- 2 measurements by up to $20 \%$. The good operational performances and data quality, routinely assessed by Calval teams, has allowed us to use SARAL/AltiKa in the fully operational Copernicus Marine Environment and Monitoring Service (CMEMS) from May 2015 onwards. The L3 and L4 Sea Level products are available on the CMEMS portal (http:/ / marine.copernicus.eu/) for the whole SARAL/AltiKa period (2013-2017).

Regional CMEMS products (Mediterranean Sea, Arctic, European Shelves, etc.) particularly benefit from SARAL/AltiKa inputs. The availability of data above $82^{\circ}$ latitude allowed us to increase the density of observation in the Arctic area, in complement to CryoSat-2. More measures have also been available near the coast. It is highlighted in Figure 7, showing the increase of measurement use to compute an Envisat/SARAL/AltiKa mean profile compared to an ERS-2/Envisat mean profile, both profiles having been estimated using the same period length, 14 years. One can notice the data gain in the coastal areas such as the Danish straits, where the availability of the previous missions was poor. The coming reprocessed data DUACS DT2018 (CMEMS V4) will benefit from this new mean profile, improving not only the products during the SARAL/AltiKa period, but also the full ERS-1/ERS-2/Envisat period through the use of this new mean profile allowing a notably better description of the coastal mesoscale.

After the end of the repetitive mission in July 2016, the degradation of the data quality due to the lack of a precise MSS was strongly mitigated by the use of MSS_CNESCLS2015 [9], and the contribution of SARAL/AltiKa in the DUACS system remain significant, though now lower than the new Jason-3 and Sentinel-3A missions. However, the data now produced with this new orbit become even still more interesting for the MSS studies as the sea level is now measured over uncharted tracks. Next versions of MSS will benefits from these dataset, notably at 10-50 km wavelength all over the ocean and on the coastal areas. This will eventually lower the error budget of the Sentinel-3-A and B mission relying on these MSS, still reinforcing the crucial contribution of SARAL/AltiKa to the Sea Level products. 


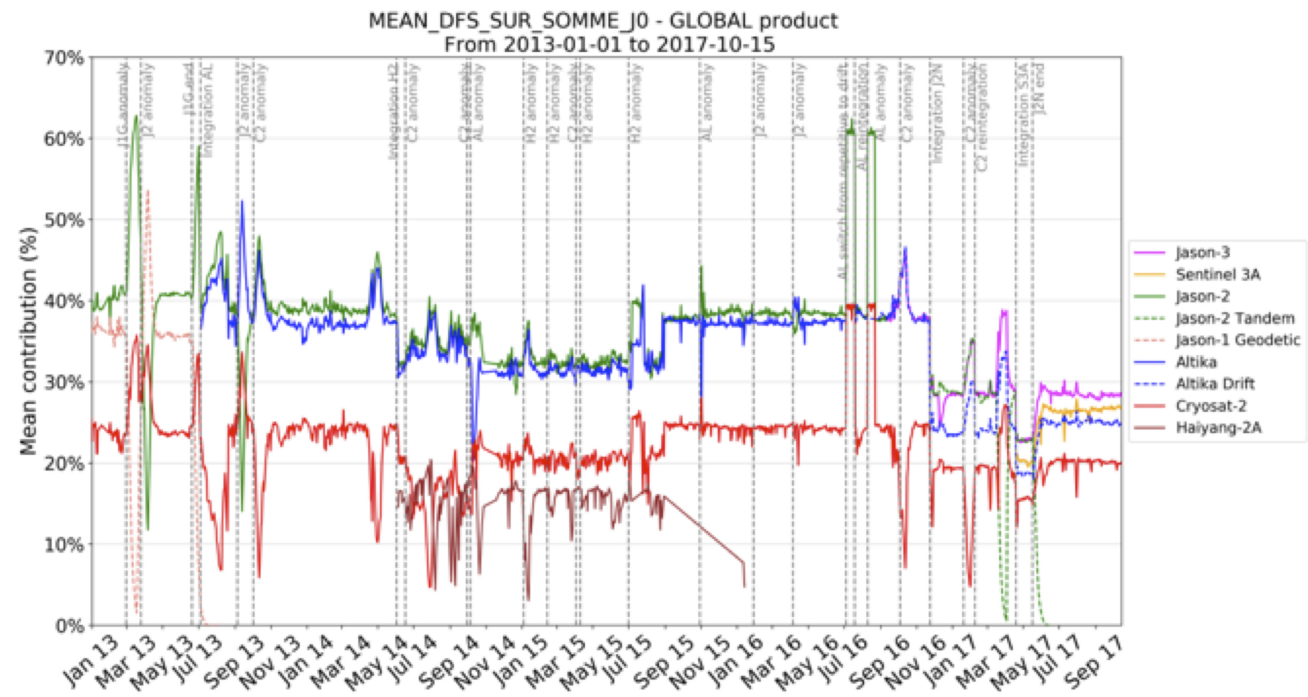

Figure 6. Relative contribution in percentage of each altimeter in the multi-mission NRT DUACS maps during the 2013-2017 period and link with altimeter events. The contribution is derived from the degrees of freedom of signal. The SARAL/AltiKa contribution is in blue, the plain curve corresponding to the repetitive period and the dotted curve to the drifting period.
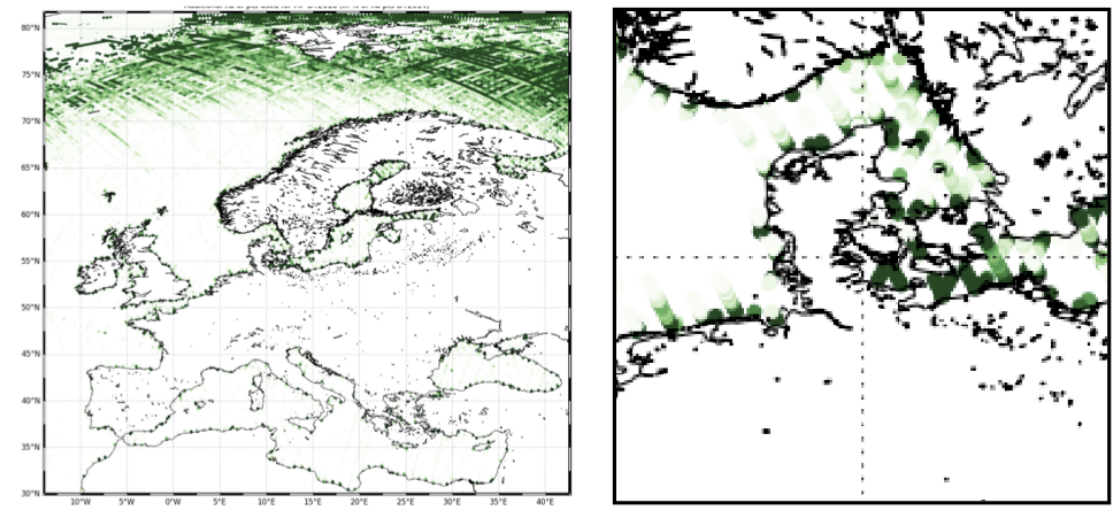

$0 \%$ $5 \%$

$10 \%$

Figure 7. Relative increase in percentage of the number of point used to compute an Envisat/SARAL/AltiKa mean profile relatively to the previous a ERS-2/Envisat mean profile over: European Seas (left); and zooming over the Danish Straits (right).

\subsubsection{Assimilation of SLA Data in the Mercator Ocean System}

SARAL/AltiKa 35-day repeat orbit altimeter is well suited for the monitoring of mesoscale variability and to complement Jason-series observations (e.g., [16]). Its low noise level due to the use of Ka-band also allows a better resolution of along-track mesoscale signals [5]. SARAL/AltiKa thus provides essential altimeter observations for global ocean analysis and forecasting. The along track SARAL/AltiKa SLA observations has been successfully assimilated in the Mercator Ocean analysis and forecasting systems since 31 July 2013, only five months after the satellite launch. We analyse here its specific contribution in addition to other altimeters for global ocean analysis and forecasts. The new Copernicus global ocean system at $1 / 12^{\circ}$ benefits from important improvements that lead to significant reduction of the analysis and forecast SLA errors. The observation errors for SST and SLA 
are now dynamically adjusted using an approach proposed by [17]. In 2015, SARAL/Altika diagnosed SLA observation errors have a global mean RMS of $3.6 \mathrm{~cm}$, comparable to the Jason-2 error but lower than the one for HY-2A and CryoSat-2. This error estimate includes the mean dynamic topography, model representativity and processing error. The lower values are around $2 \mathrm{~cm}$ in the centre of the gyres but can reach more than $10 \mathrm{~cm}$ in high energetic regions, such as western boundary currents and the Antarctic circumpolar current.

Observing System Evaluation (OSE) experiments, covering the year 2015, have been carried out with this new system to assess the impact of an increase number of altimeters. Figure 8 shows the relative reduction of the SSH forecast Mean Square Error (MSE) due to the assimilation of SARAL/AltiKa ; Cryosat-2, Jason-2 and HY-2A being already assimilated. The impact is significant and highly regionally dependent. Innovation (observation minus model forecast) statistics are computed with Cryosat-2, Jason-2 and HY-2A data. The normalized SLA error difference between the experiment without and with SARAL/AltiKa SLA assimilated reaches $40 \%$ at mid-latitudes, whereas, in the same OSE but with the global $1 / 4^{\circ}$ system, it reaches only $25 \%$ (not shown). This could be interpreted as a need of a higher density of observation to constrain the smaller scales of the $1 / 12^{\circ}$ ocean model compared to the $1 / 4^{\circ}$ system. The assimilation of SARAL/AltiKa SLA allows a gain of 0.8 day to get the same level of forecast error but without SARAL/AltiKa. The comparison of the estimated surface velocity fields in the different OSEs with subsurface drifters also shows an improvement with the addition of SARAL/AltiKa, even if three altimeter data sets have already been assimilated.

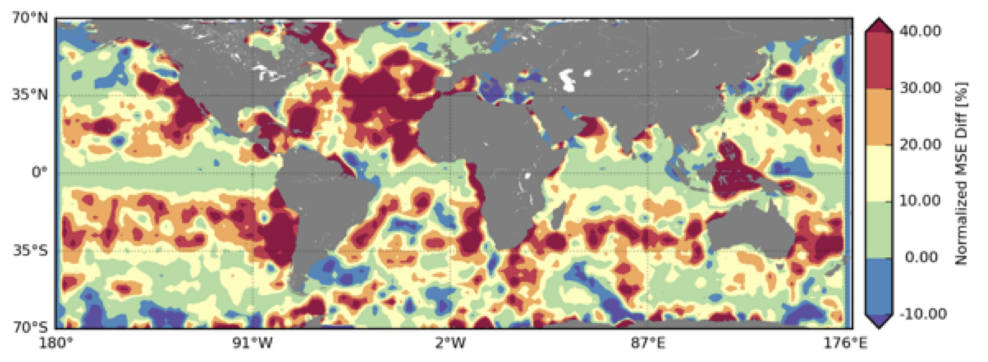

Figure 8. Normalized Mean Square forecast Error difference in percentage between the experiments assimilating three and four altimeter data sets under CryoSat-2, Jason-2 and HY-2A tracks with the $1 / 12^{\circ}$ global system: (innov 3 alt $)^{2}-(\text { innov } 4 \text { alt })^{2} /(\text { innov } 3 \text { alt })^{2}-$ SARAL/AltiKa being the fourth altimeter.

\subsubsection{Assimilation of SWH Data Into the Météo-France Operational Weather Forecast System}

SARAL/AltiKa provides a very accurate SWH to improve the operational wave forecasting of Météo-France. During the last three years of operational use of SARAL/AltiKa, it has been demonstrated that the operational wave forecast is significantly improved for the global and regional scales. In addition, SARAL/AltiKa plays an important role in the correction of sea state in coastal zones. Figure 9 shows a snapshot of SWH from the operational Météo-France wave model (MFWAM) of a resolution of $10 \mathrm{~km}$ and dedicated to European seas during the storm happened in March 2016. The MFWAM model is routinely using SARAL/AltiKa, Jason-2 and CryoSat-2 altimeters wave data. The Jason-2 track overlaid on the snapshot indicates the accurate forecast at the peak of the event on 27 March 2016 at 21:00 UTC. The SARAL/AltiKa wave data were also used efficiently in the validation of high resolution coastal wave model of $200 \mathrm{~m}$ of resolution implemented at Météo-France. Figure 10 indicates a snapshot of SWH during the the storm of the 8 February 2016 which generated high waves in the English channel near the French coasts at Cherbourg. The SARAL/AltiKa track passing over the English channel and close to the French coast reveals the accurate forecast of the coastal model. Moreover with SARAL/AltiKa the assimilation of small wave heights (less than $1 \mathrm{~m}$ ) in regional models MFWAM has been significantly improved for closed seas and lakes. 


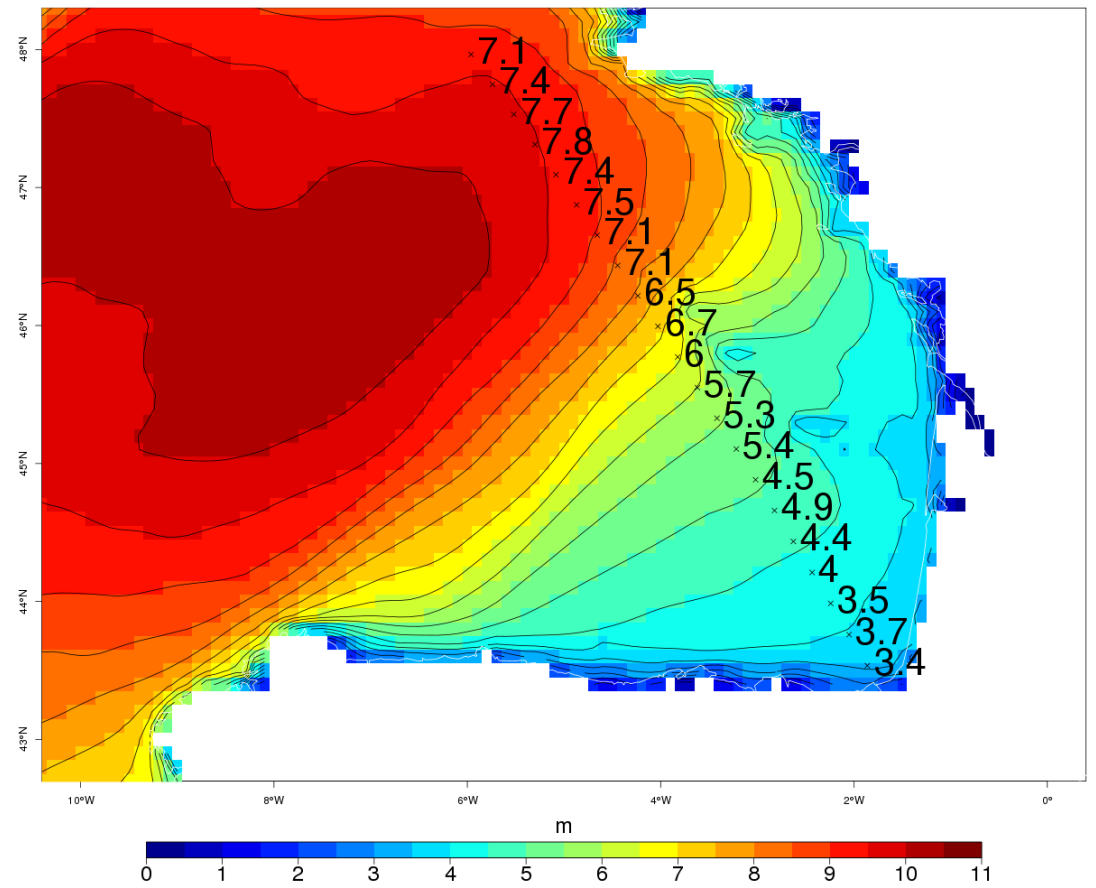

Figure 9. SWH (in $\mathrm{m}$ ) from the regional wave model MFWAM dedicated to European seas on 27 March 2016 at 21:00 (UTC). The model MFWAM is driven by wind forcing from the atmospheric model of Météo-France ARPEGE (Action de Recherche pour Petite Echelle Grande Echelle) with a resolution of $10 \mathrm{~km}$. The Jason-2 track in the gulf of Biscay indicates SWH (in m) during the peak of the event. SWH of more than $9 \mathrm{~m}$ was recorded off shore of the Brittany coast.

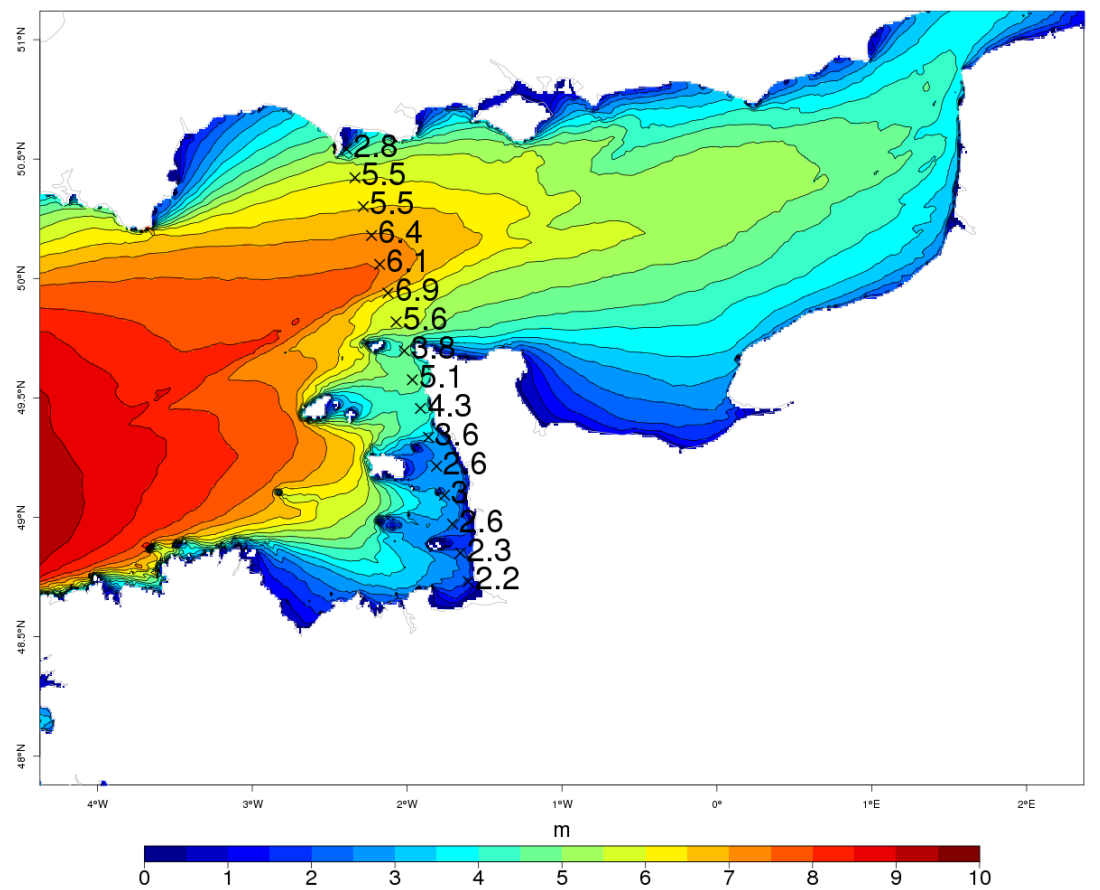

Figure 10. SWH (in $\mathrm{m}$ ) in the English channel from the operational coastal model WaveWatch3 (WW3) with unstructured grid of a resolution of $200 \mathrm{~m}$ during the event of 8 February 2016 at 06:00 UTC. The model is driven by the wind forcing from the model ARPEGE. The SARAL/AltiKa track is overlaid and indicates SWH (in $\mathrm{m}$ ) at the peak of the event near the coast. 


\subsection{Accuracy of SWH Data}

\section{The Comparative Analysis of Ku and Ka-Band Altimeters for Wave Observations}

The measurements from both $\mathrm{Ku}-$ and Ka-band altimeters have been available concurrently. This case presented here aims to evaluate the suitability of both frequencies for wave and inland water studies. For this study the SARAL/AltiKa and Jason-2 data for year 2013 has been used. NOAA National Data Buoy Center (NDBC) buoy data have been used extensively to validate both SARAL/AltiKa and Jason-2 data individually for 2013. The SWH from both altimeters are collocated with NDBC buoy data at spatial and temporal intervals of $25 \mathrm{~km}$ and $30 \mathrm{~min}$, respectively. Analysis has been carried out for various sea states and for the mid-latitude and tropical belts. The collocated points where difference of altimeter and observation is larger than three times the standard deviation of the difference are excluded from the analysis. The wave data for Cycle 4 from SARAL/AltiKa and Cycle 185 of Jason-2 have been analyzed over the Hudson's Bay area of Canada. This is the second largest bay in the world with average depth below $100 \mathrm{~m}$ and maximum depth of $270 \mathrm{~m}$. The bathymetry of this region is shown in Figure 11a. Most of the Ku band altimeters does not show data availability at this shallow depth. Jason-2, for example, does not have data available over this region.
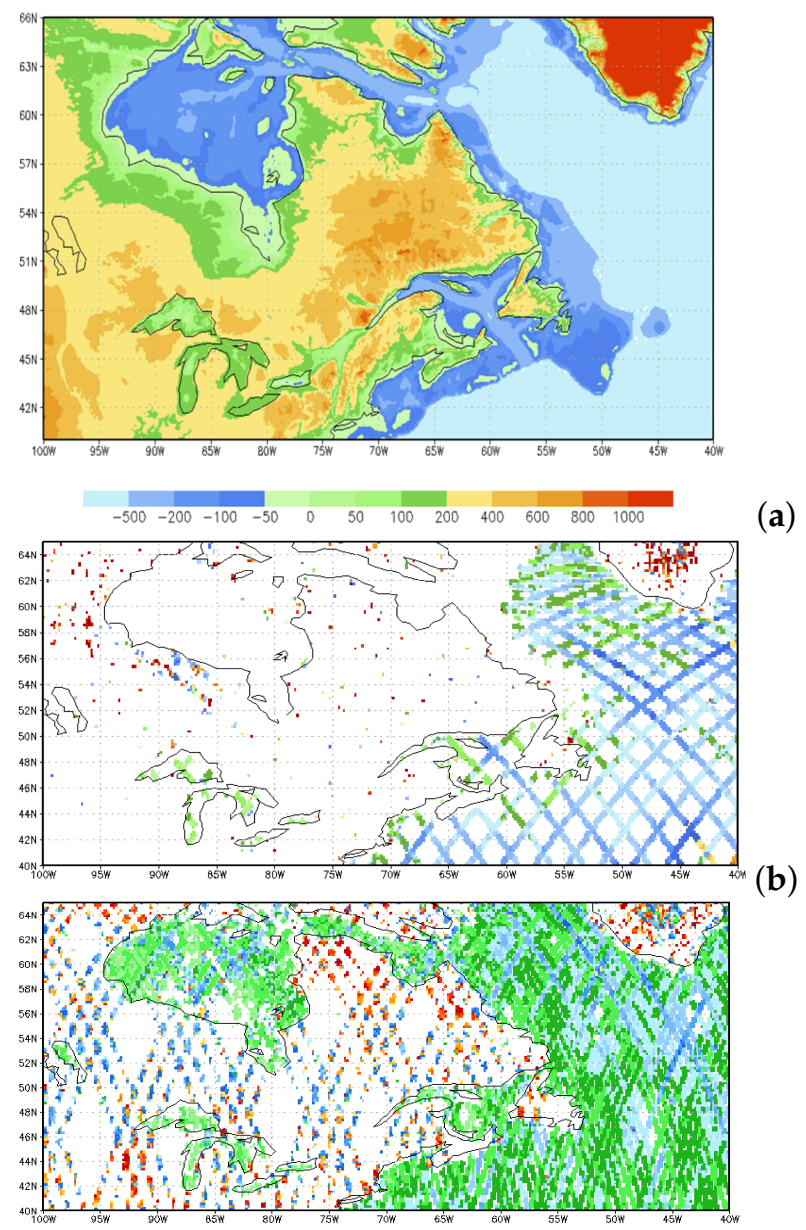

(b)

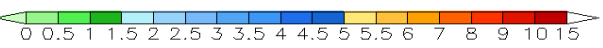

(c)

Figure 11. Availability of SWH data over very shallow depth from SARAL/Altika as compared to Jason-2. The example is Hudson Bay, with average depth of $100 \mathrm{~m}$ and maximum depth of $270 \mathrm{~m}$ : (a) bathymetry of Hudson Bay; (b) SWH from Jason-2; and (c) SWH from SARAL/AltiKa. 
However, with emergence of SARAL/AltiKa, scientific fraternity is fortunate to get the valuable data from altimeter over this area. This opens the door to several applications for shallow waters including dams and reservoirs using Ka-band altimetry. Apart from being excellent in shallow water, Ka-band altimetry is known for its better approachability towards the coast. For example, over Indian subcontinent, the SWH data across a transect along $18^{\circ} \mathrm{N}$ has been shown in Figure 12 for Cycle 4 of SARAL/AltiKa and Cycle 185 of Jason-2. Very clearly, for the coast at about $83.5^{\circ} \mathrm{E}$ (marked by the yellow line), the SARAL/AltiKa has much better approachability, up to $84.2^{\circ} \mathrm{E}$, as compared to Jason-2 $\left(85.8^{\circ} \mathrm{E}\right)$. The comparison of SARAL/AltiKa and Jason- 2 with NDBC buoys clearly shows that in calm and moderate sea conditions when SWH is between $0-2.5 \mathrm{~m}$ the performance of the SARAL/AltiKa is better than Jason-2 (Figure 13). The comparison of SWH with buoy observations for mid-latitudes and tropics clearly indicates that SARAL/AltiKa has excellent capabilities of observing waves for both the belts (Figure 14).

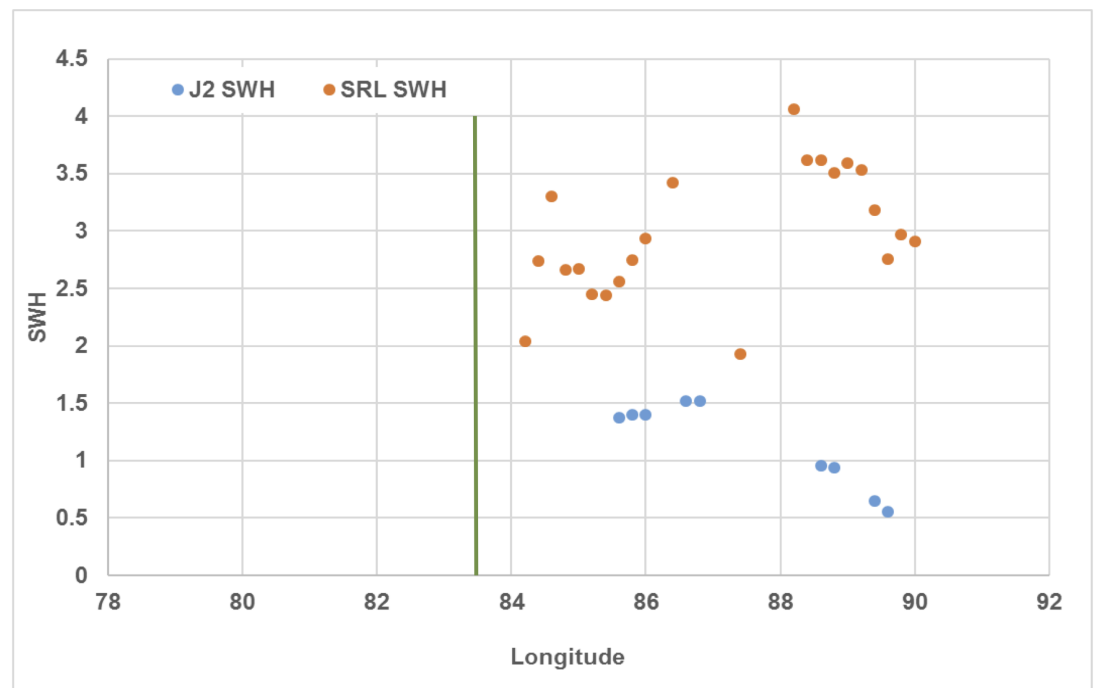

Figure 12. Availability of valid SWH data from SARAL/Altika and Jason-2 for transect along $18^{\circ} \mathrm{N}$ showing better available data near coast marked by green line.

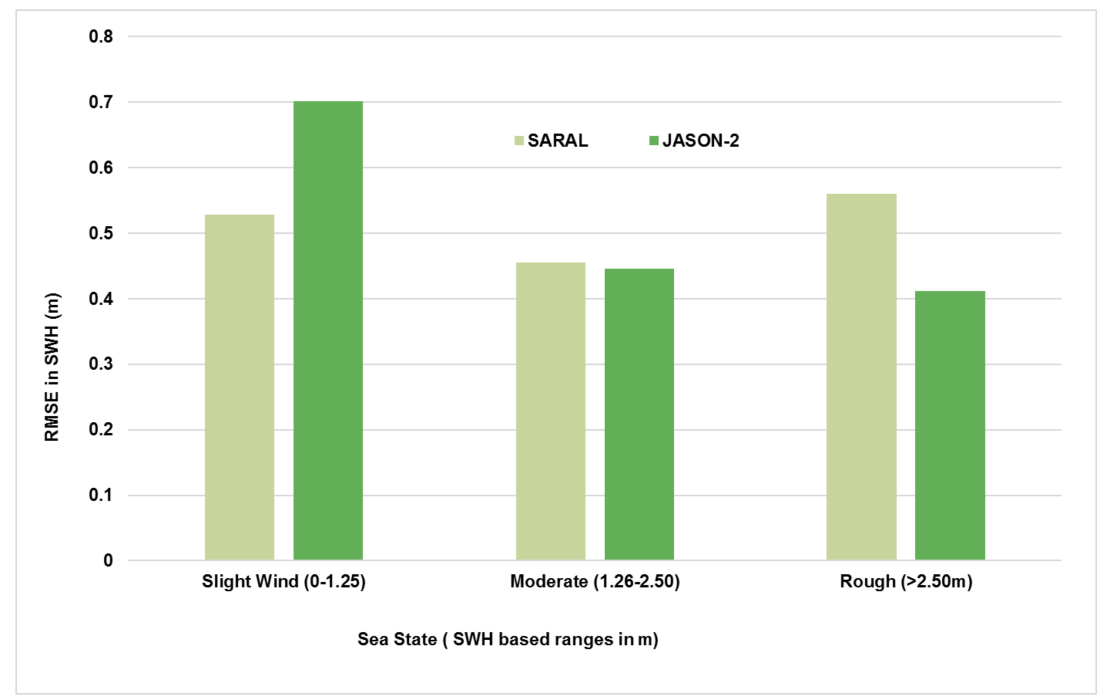

Figure 13. RMSE of SARAL/AltiKa and Jason-2 SWH with respect to buoy observed wave in various sea state categorized on basis of SWH. 


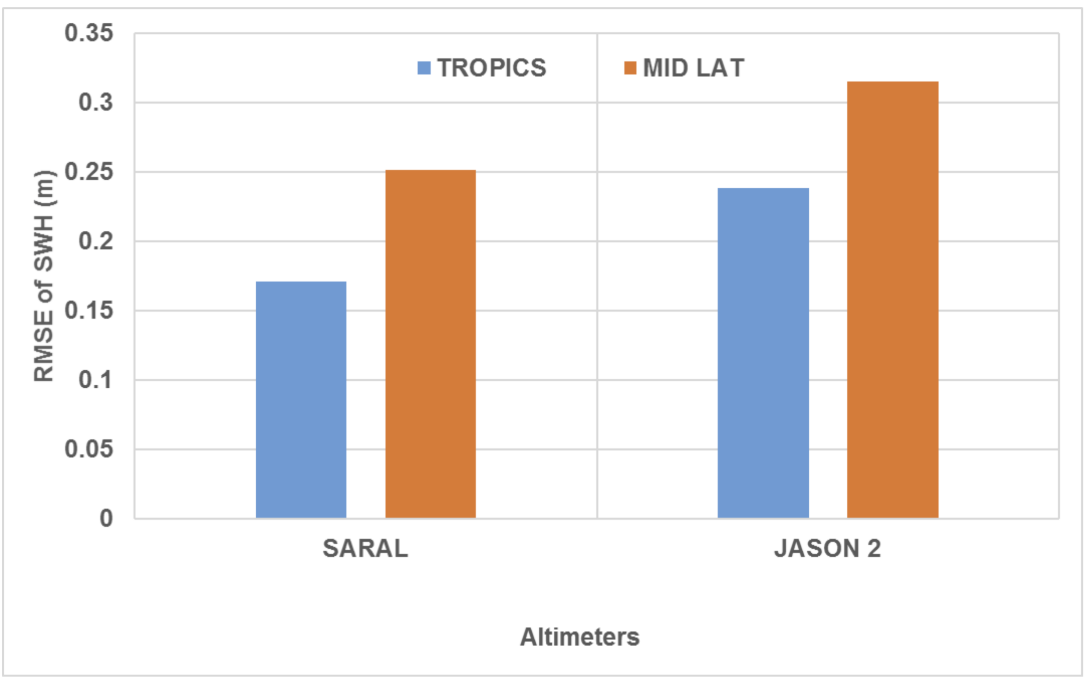

Figure 14. RMSE of SARAL/Jason-2 SWH with respect to buoy observed wave in mid-latitude $\left(30-60^{\circ} \mathrm{N}\right)$ and Tropics $\left(0-30^{\circ} \mathrm{N}\right)$.

\section{Inland Waters}

Worldwide, the number of operational ground stations for lake and river water levels and discharge monitoring has continuously decreased since the 1970s. Meanwhile, satellite capabilities for inland waters studies have emerged. In particular, many published studies have demonstrated that satellite altimetry allows measuring accurately water level along rivers and lakes $[18,19]$. For rivers, satellite altimetry has evolved from investigation of water height retrieval to the monitoring and discharge estimations. For lakes, it has evolved to the monitoring of water storage change [20]. Recent research focuses on integrating altimetry with other remote sensing techniques and hydraulic models to deal with key inland water resources issues such as flood (discharge, water spread and volume), water level monitoring (even in highly braided/fragmented river systems), rating curve generation for remote locations, reservoir operations, calibration of river/lake models, etc. Before it moves to a drifting orbit, SARAL/AltiKa contributes to meeting the growing demand of altimetry data for hydrological studies. Three examples of SARAL/Altika applications regarding rivers and lakes are provided in the following.

\subsection{Rivers}

\subsubsection{Comparative Analysis of Water Level Retrieval Using Ku and Ka-Band Altimeters Over} Brahmaputra River

Over inland water bodies, presence of sand bars, islands and vegetation contaminate radar return echo. Hence, with narrow footprint in Ka-band, altimeters enhance the possibilities of better data acquisition over the inland water bodies with multiple features. The decrease in time decorrelation between successive echoes has increased the pulse repetition frequency to $4000 \mathrm{~Hz}$ in Ka-band as compared to $2000 \mathrm{~Hz}$ with Ku-band altimeters. The limitation with higher frequency is that it has higher rainfall attenuation with increasing rainfall intensity, although total data loss due to this is less than $5 \%$. In this study, river water levels were retrieved using Jason-2 and SARAL/AltiKa waveform datasets over Brahmaputra river for 2013. Three passes of Jason-2 (track number 242, 53 and 166) over the Brahmaputra river and nearby tracks of SARAL/AltiKa (track number 537, 810 and 438) were selected (see Figure 15). Time of pass of SARAL/AltiKa tracks and nearby pass data of Jason-2 were chosen. Beta parameter algorithm has been applied using the $20-\mathrm{Hz}$ (Jason-2) and $40-\mathrm{Hz}$ (AltiKa) waveform datasets to retrieve the river water levels with respect to mean sea level. A comparative analysis was carried out to assess the Ku-band vs. Ka-band altimetry performance for the river water 
level retrievals. Individual tracks were compared; it was found that SARAL/AltiKa performs slightly better for the upstream tracks, i.e., 537 vs. 242 and 810 vs. 53. For the downstream track where braiding pattern is high (track number 166, Jason-2 and 438, SARAL/AltiKa), Jason-2 performance decreased sharply (RMSE $1.19 \mathrm{~m}$, Jason-2 vs. 0.41, SARAL/AltiKa) as compared to SARAL/AltiKa. This may be attributed due to higher band width $(500 \mathrm{MHz})$ in Ka-band altimetry which provides shorter pulse duration; hence increase the vertical range resolution $(0.3 \mathrm{~m})$ as well as spatial resolution. Figure 16a,b presents the overall performance of the SARAL/AltiKa and Jason-2, respectively, taking into account all three tracks. The improved accuracy over the braided rivers highlight the high frequency Ka-band altimeter performance.

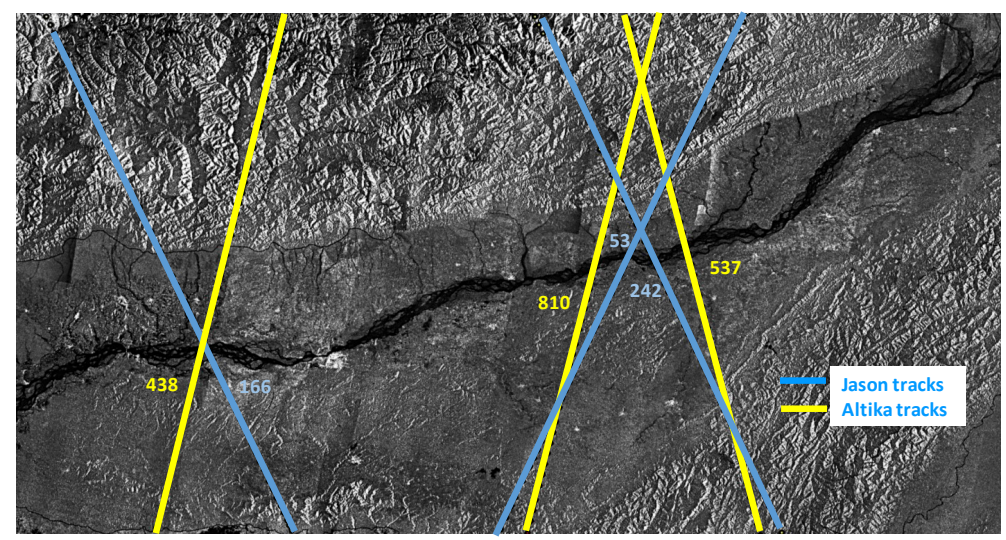

Figure 15. Brahmaputra river along with Jason-2 and SARAL/AltiKa tracks taken for the comparative analysis.
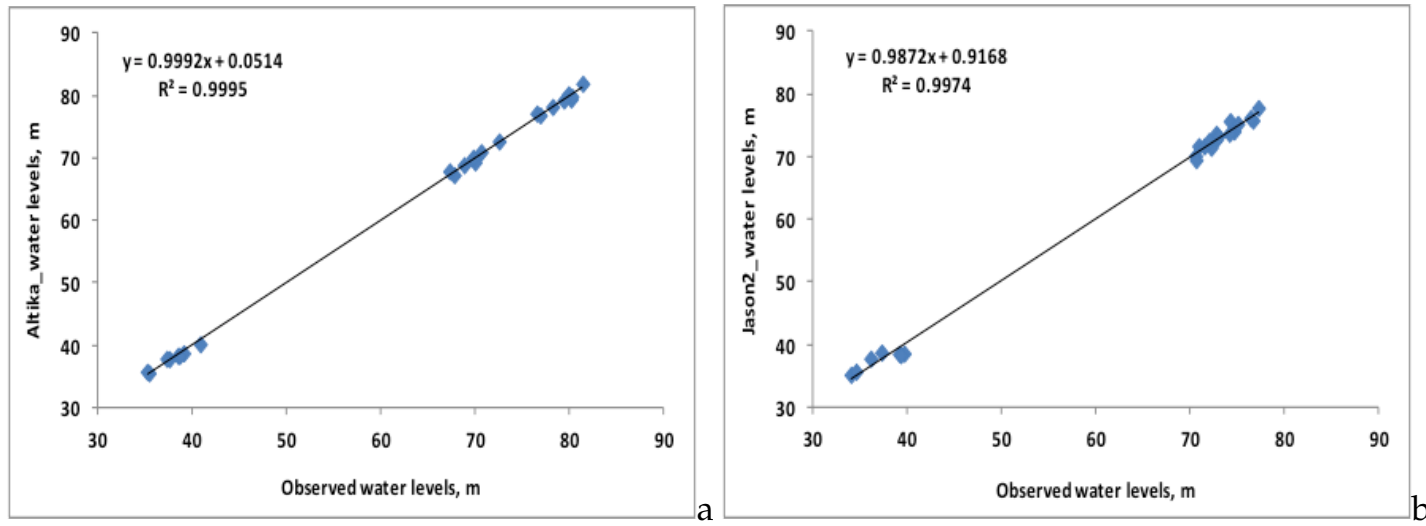

Figure 16. Overall relationship between observed versus retrieved water levels taking into account all study tracks: (a) SARAL/AltiKa ; and Jason-2 (b).

\subsubsection{Discharge Estimates in the Congo Basin From Validated SARAL/AltiKa Measurements}

The Congo basin, with an average discharge of $40,600 \mathrm{~m}^{3} / \mathrm{s}$ and undergoing a $10 \%$ inter-annual variability [21,22], is the second largest hydrological basin on Earth. However, it is also one of the least monitored. Today, only a few tens of gauges still monitor the water level changes in the basin. In such a context, satellite altimetry provides a complement of information of highest interest [23]. A limited amount of works has been conducted to date to assess the quality of the SARAL/AltiKa data over rivers [24-26]. In the present study, we use the ranges issued at $40 \mathrm{~Hz}$ by the ICE1 retracking algorithm and applied the corrections for propagation in the atmosphere provided by global models such as ECMWF and Global Ionosphere Maps (GIM). The segment of height profiles at the crossing between the orbit ground track and a river reach (so called Virtual Stations) were subsequently processed with the median value of manually selected measurements being finally computed as the water height. 
This procedure follows the results presented by $[27,28]$ and has been widely used since then (see reviews in $[18,20])$. Two methods are usually used to assess the quality of the altimetry-derived series of water level: external comparison with in-situ gauge reading and internal comparison at cross-overs.

In the present study, we focus on the second method since the Congo basin is almost devoid of gauges. In addition, fortunately, the SARAL orbit forms crossovers at 1.5 day time difference over several rivers in the basin. Comparing water level measurements collected 1.5 days apart is not fully satisfactory but the positive side is that the difference is a conservative (over)estimate of the true measurement error since it includes the natural level variations. We selected 25 locations where the ascending and descending passes cross a river reach at less than $20 \mathrm{~km}$, the maximum distance that we considered as relevant for a cross-over analysis. Within this dataset, the five cases correspond to reaches less than $250 \mathrm{~m}$ in width and 15 to reaches wider than $500 \mathrm{~m}$ (Figure 17). The colour code in Figure 17 stands for the standard deviation between the time series at the ascending and descending passes. The cumulative distribution of the cycle-by-cycle difference between all the measurement pairs (inset in Figure 17) shows that $90 \%$ of the measurement pairs present a difference in height less than $25 \mathrm{~cm}$. The present result is consistent with the 10-30 cm errors found by $[24,25]$ in the Ganga-Bramapoutra basin and by [26] in the Amazon basin. Noteworthy, there is no straightforward relationship with the width of the reach.

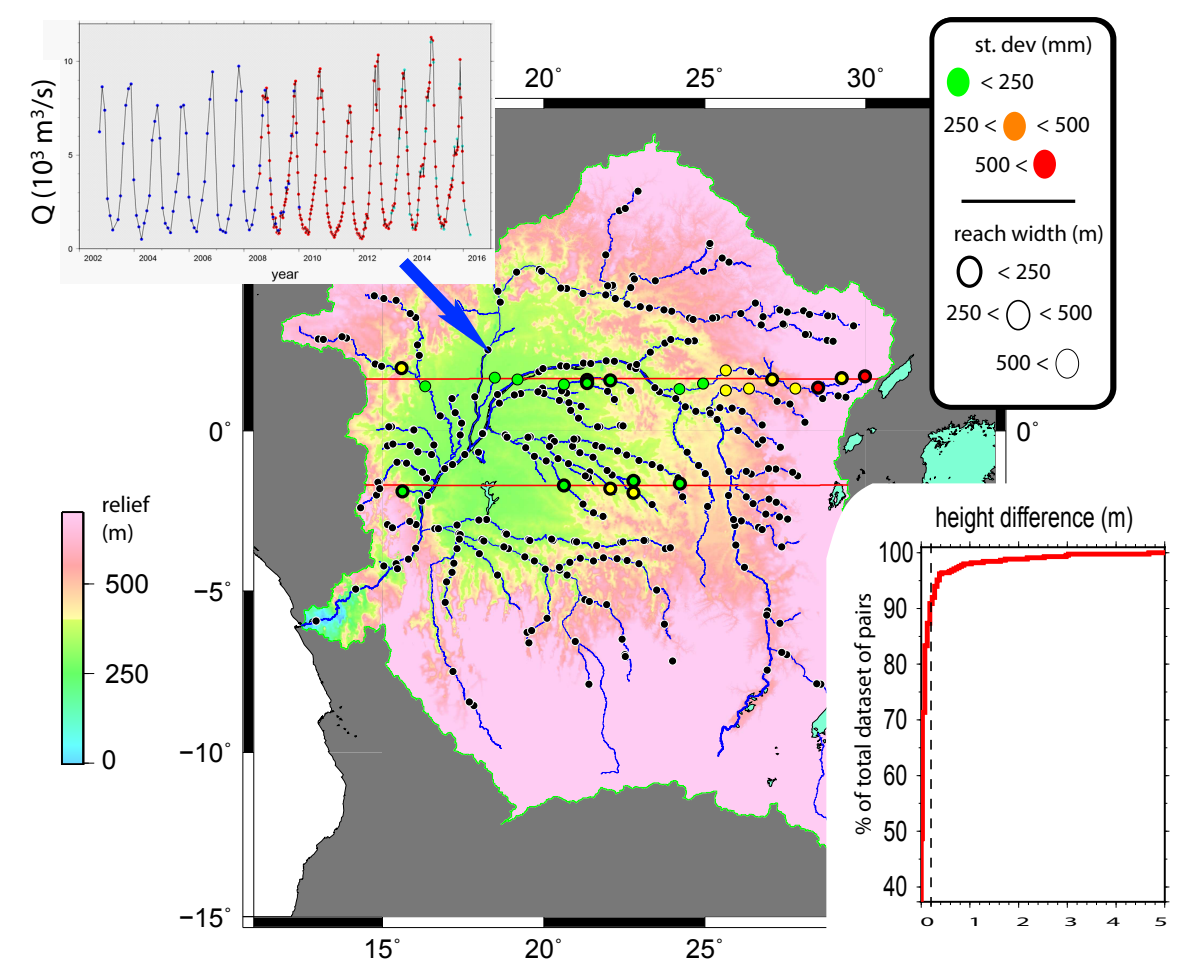

Figure 17. The Congo basin. The locations of the 350 SARAL/AltiKa Virtual Stations are shown with black dots. The $+1.595^{\circ}$ and $-1.677^{\circ}$ parallels in red are where the SARAL/AltiKa orbit forms crossover at 1.5 day temporal difference. The Virtual Stations used for the accuracy assessment at cross-overs are coded according the standard deviation between the two SARAL/AltiKa series of water level and the reach width, as recalled in the upper right inset. The cumulative histogram of the differences between measurement pairs is shown in the lower right inset. The dotted bar outlines the value of $20 \mathrm{~cm}$ in difference achieved by $90 \%$ of the population of height pairs. An example of Envisat + Jason-2 + SARAL/AltiKa discharge series on the Ubangui River derived from the rating curve established combining SARAL/AltiKa levels and MGB discharge is presented in the left hand inset. 
One of the most important applications of water level measurements is their conversion into discharge estimates. Discharge estimates were obtained through the following steps: (1) same as first proposed by [29], compute distributed discharge between 2013 and mid-2014 by means of the rain-discharge model of the Institute of Hydraulic Research of Brazil (MGB-IPH) fed with rain fields from the JAXA/NASA Tropical Rainfall Measuring Mission (TRMM) mission; (2) compute height-discharge power laws compliant with the Manning equation; and (3) apply these rating curves to the SARAL/AltiKa series to derive discharge series. An example of such a discharge series is presented in the left hand inset of Figure 17. At this location on the Ubangui River, the Envisat/SARAL orbit and the Jason- 2 orbit form a crossover right over the Ubangui River. Thus, a long continuous discharge series could be derived by applying the SARAL/AltiKa rating curve altogether to the Envisat, Jason-2 and SARAL/AltiKa times series of water level.

Overall, SARAL/AltiKa altimetry shows to be a powerful tool to estimate water levels with errors around $20 \mathrm{~cm}$ at more than 300 locations throughout the Congo basin, hence discharge in such a basin almost devoid of ground monitoring.

\subsection{Lakes}

\section{A Case Study of the Tibetan Lakes}

The Tibetan plateau is known by climatologists as the "Third Pole". It is located northeast of the Himalayan mountain range and has an average altitude of more than $4000 \mathrm{~m}$. The Tibetan Plateau covers an area of 2.5 million square kilometres mainly made up of permafrost and covered by more than 1000 lakes of sizes larger than $1 \mathrm{~km}^{2}$. Furthermore, the Tibetan Plateau is one of the regions of the world most sensitive to climate change since the average increase in temperature over the last few decades has been more than double the average for the rest of the Earth [30]. In such context, it has been demonstrated in many studies that lakes level changes in time are essential variables to track climate change impacts on water resources over the Tibetan plateau ([31], and many others). For example, an increase in temperature leads to an increase in evaporation but also accelerates glacier and permafrost thawing [32]. Changes in precipitation over long period of time also have direct impact on water contained in lakes [33]. Moreover it has been also shown in several studies that the lake level response time to climate change may be observable only over decades [20]. This has naturally placed the satellite altimetry as a useful tool for studying these links between lakes and climate changes. Due to its orbit the SARAL/AltiKa mission allows to monitor level changes on a large number of lakes over the Tibetan Plateau. It has moreover a very high accuracy over lakes, much better than that of Envisat or ERS-2 (placed on the same orbit) as shown in [34]. This is likely due to the choice of Ka band allowing a significant reduction of the footprint, and of the small ionospheric effect on the range measurement. The interest of this satellite is therefore significant since it allows extending the existing time series on the lakes over the Tibetan Plateau and may exhibit long term changes in an improved accuracy. Combining SARAL/Altika over lakes with other satellite altimeters is easily performed as a result of overlapping time of observations as shown in Figure 18. Inter-satellite instrumental biases are removed then to produce decadal level changes of lakes and thus observe and link the lake level with climate change (Figures 19-21). From these results we may draw two main conclusions:

- The responses of lakes to climate changes are not the same from one lake to another one and needs long term observations to be highlighted. For example, the Ziling lake which has grew up during more than 15 years seems over the last years to reach an equilibrium state which has been seen only with the SARAL/AltiKa measurements. It may be different for other lakes, as seen in Figures 20 and 21. It has been shown in [20] that long term changes of lakes over the Tibetan Plateau are highly variable and depend on regional climate change as well as the lake's bathymetry. 
- Only SARAL/AltiKa allows extracting short term variability of water level of these lakes, since the other missions (ERS-2, Envisat, CryoSat-2, TOPEX/Poseidon, Jason-1 and Jason-2) were not precise enough to show these seasonal variabilities.

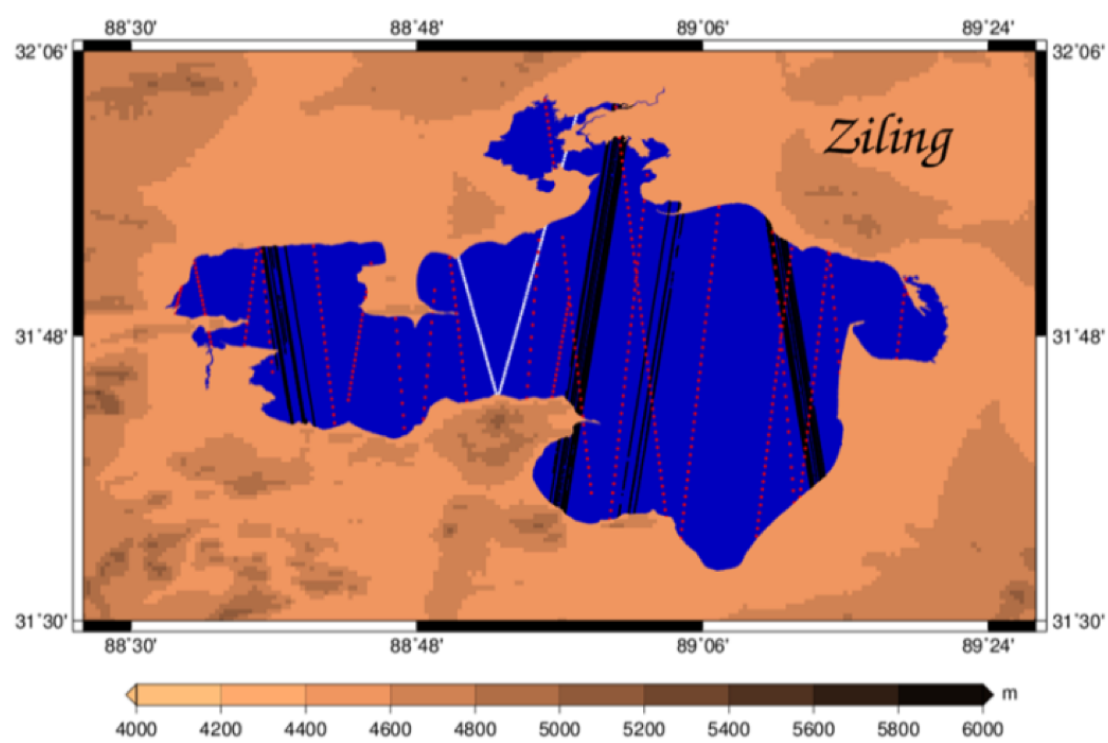

Lake Ziling

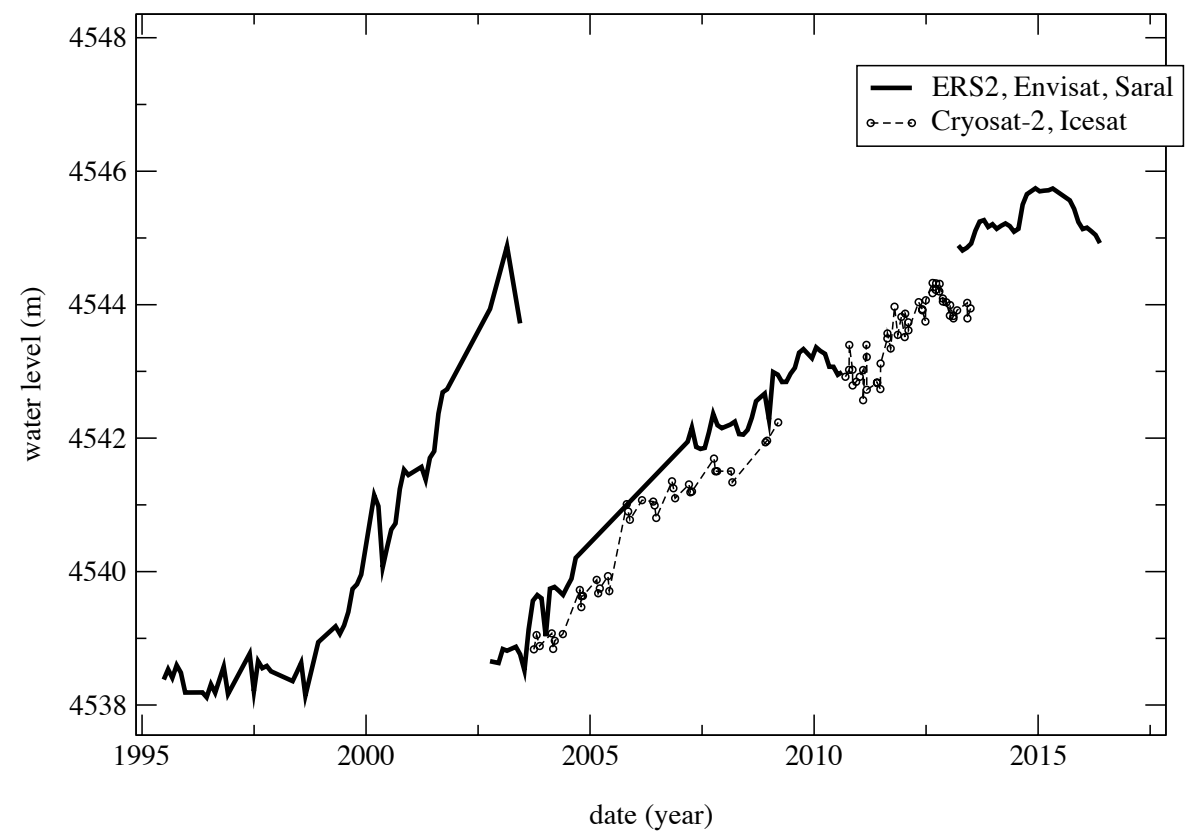

Figure 18. Tracks of satellite altimeters (black: ICESat; red: CryoSat-2; and white: ERS-2, Envisat and SARAL/AltiKa ) over the Ziling Lake, one of the largest of the Tibetan Plateau (top); and water level changes from each satellite before correcting from inter-satellite tracks from 1995 to 2016 (bottom). 


\section{Lake Ziling}

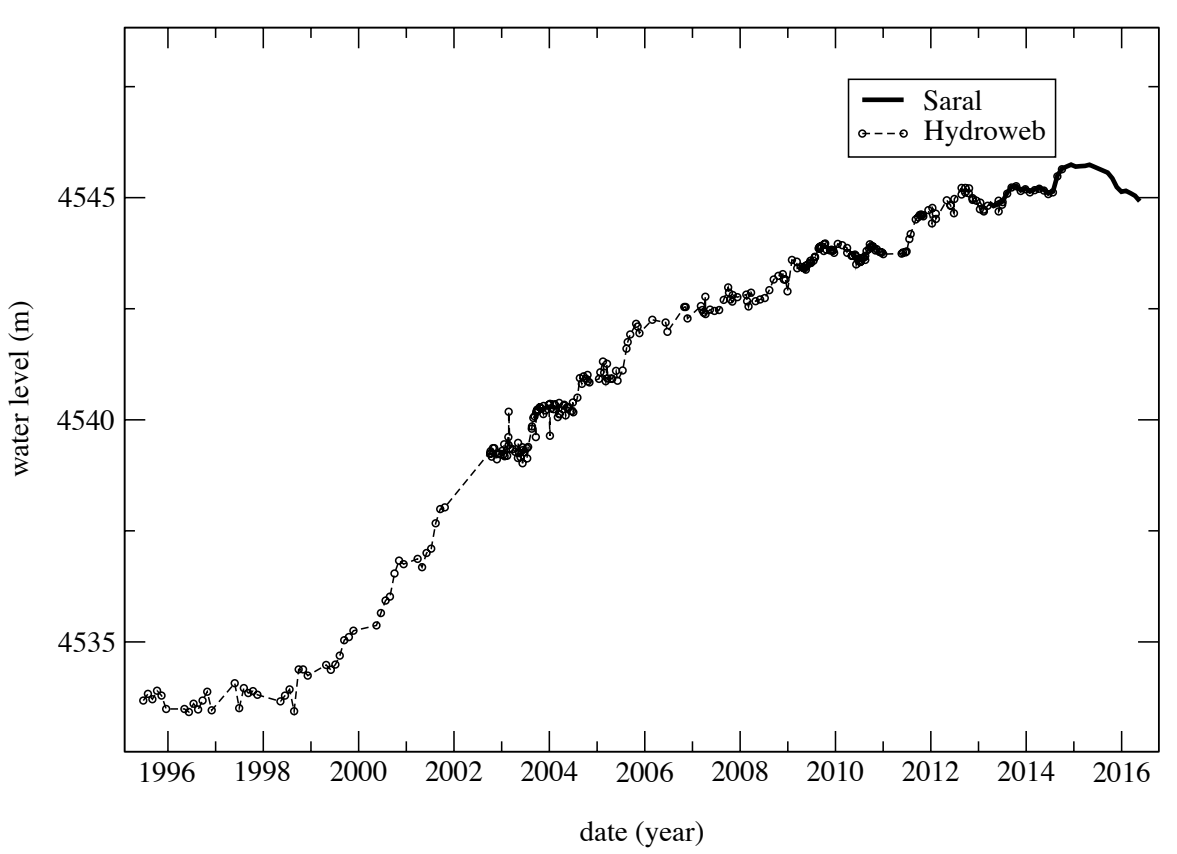

Figure 19. Water level change of the Ziling Lake from a multi-satellite data processing after removing the inter-satellite biases. After a long period of increasing starting in 1999, the lake level has stabilized in 2013/2014 (extracted from Hydroweb database http:/ /hydroweb.theia-land.fr/ and from SARAL/AltiKa data processing for the period 2013-2016).

\section{Lake Namco}

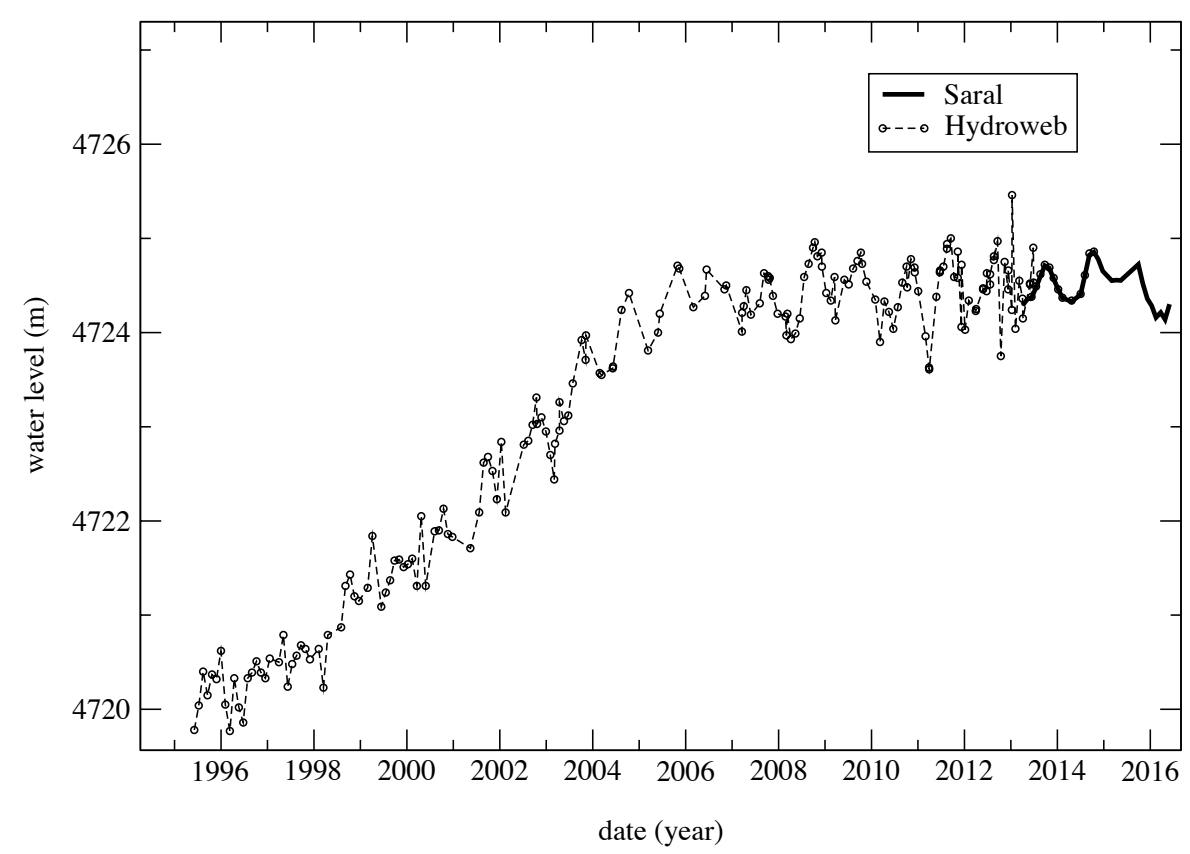

Figure 20. Water level change of the Namco lake from a multi-satellite data processing. After a long period of increasing, the lake level has stabilized in 2006/2007 (extracted from Hydroweb database http:/ /hydroweb.theia-land.fr/ and from SARAL/AltiKa data processing for the period 2013-2016). 


\section{Lake Ngoring-Co}

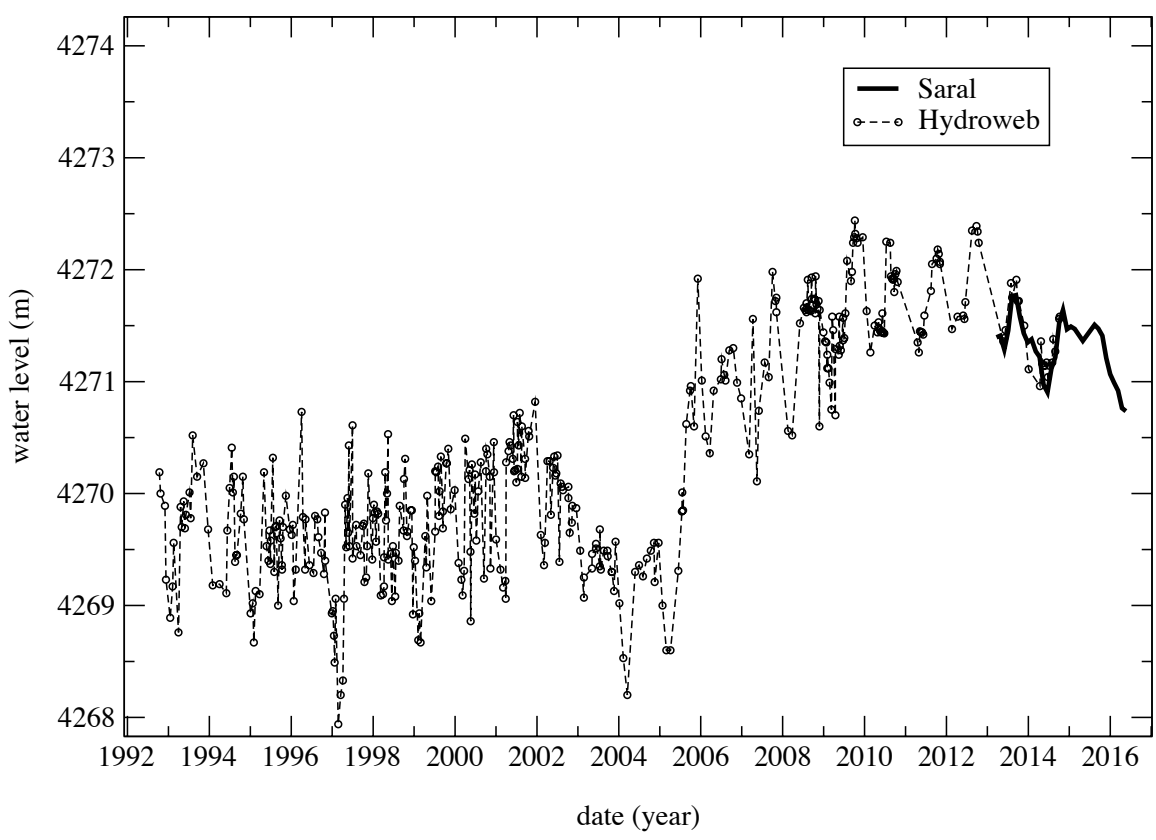

Figure 21. Water level change of Ngoring-Co Lake from a multi-satellite data processing. The lake was at equilibrium between 1992 and 2005 and has suddenly grown since 2006 to reach in a short time a new equilibrium, which slightly decreased after 2013 (extracted from Hydroweb database http:/ /hydroweb.theia-land.fr/ and from SARAL/AltiKa data processing for the period 2013-2016).

\section{Ice}

For the last few decades, terrestrial ice has undergone large change and its survey is of a prime importance for climate study. Altimetry is one of the most powerful tools for ice sheet mass balance, sea ice thickness and iceberg detection studies. An altimeter operating in Ka- instead of Ku-band is far from being insignificant for these studies. The decrease of penetration depth within the snow, from 2 to $12 \mathrm{~m}$ for the Ku-band to less than $1 \mathrm{~m}$ for the Ka-band ensures the measurement of the snow surface. Moreover, the higher waveform rate and narrowed footprint of SARAL/AltiKa allows to better sample the small scale features and to better track the elevation transition. It is suitable to map the surface undulations or large crevasses above ice sheet or to detect leads on sea ice or small icebergs. Moreover, SARAL/AltiKa being on the same historical 35-day orbit than ERS-1-2 and Envisat allows to extend the survey for more than 20 years [35].

For sea ice, this phenomenon also seems to play a role but the major SARAL/AltiKa contribution yields from the reduced antenna aperture and in higher spatial resolution than previous altimeters. Indeed, the first echo is more likely to be at nadir decreasing influence of the off-nadir signal that often affects the retrieval measurement. Some studies in this issue confirm the ability of SARAL/AltiKa to detect leads and coastal polynyas as well as to represent spatial and temporal dynamics of water openings. Moreover, a meaningful contribution is the high sensitivity of the Ka-band backscatter to the snow and ice state, due to the altimeter wavelength. A few $\mathrm{dB}$ change may occur in a few weeks for any kind of snow or ice surface, even in the central part of the Antarctica ice sheet. It is observed in [36] a significant decrease of up to $15 \mathrm{~dB}$ at the end of ice season over Lake Baikal. The field measurements acquired along the SARAL/AltiKa tracks in Spring 2013 and Spring 2014 allow to suggest an important role of ice metamorphism and re-crystallisation. 


\subsection{Ice Sheet}

\section{Monitoring of the Antarctic Ice Sheet}

Altimetry is probably one of the most powerful tools for ice sheet observation. Our vision of the Antarctic ice sheet has been deeply transformed since the launch of the ERS-1 satellite in 1991. With the launch of ERS-2, Envisat and SARAL/AltiKa, the series of altimetric observations now provides more than 20 years of continuous and homogeneous observations that allow monitoring of the shape and volume of ice sheets. The topography deduced from altimetry is one of the relevant parameters revealing the processes acting on ice sheet. Moreover, altimeter also provides other parameters such as backscatter and waveform shape [4] that give information on the surface roughness or snow pack characteristics.

The most surprising features of Ka-band observations above the Antarctica ice sheet is the very large space and time variability of the backscatter. While the Ku-band variability was about $0.5 \mathrm{~dB}$ over few cycles, it can reach 3 or $4 \mathrm{~dB}$ in Ka-band. This unexplained observation probably comes from the small wavelength $(0.8 \mathrm{~cm}$ instead of $2.3 \mathrm{~cm})$ that is very sensitive to snow metamorphism such as surface hoar. These structures are related to snow drift and sublimation and is one of the most unknown of the polar snow. Thus, one of the major limitation of radar altimeter above ice sheet is the penetration of the radar wave within the dry snowpack. For the classical Ku-band used by altimeters, the penetration reaches a few $\mathrm{m}$. The slightest changes of surface echo or of volume echo affect the height retrieval. At the seasonal scale, the impact on height can be of few tens of centimetres. Moreover, this penetration may induce a long term artificial change in height caused by either change in the surface or snowpack properties. On the other hand, volume echo contains few interesting information on snow stratification and on ice grain size, the two volume components of Ku band. [37] show that the penetration depth in Ka-band is indeed between $50 \mathrm{~cm}$ and $1 \mathrm{~m}$ (see Figure 22). Moreover, they show that the stratification of the snow pack does not play a role in the volume component, the scattering by ice grain being the unique physics. The comparison between $\mathrm{Ku}$ and Ka-band may then correct from the penetration error and help in retrieve some snowpack parameter.

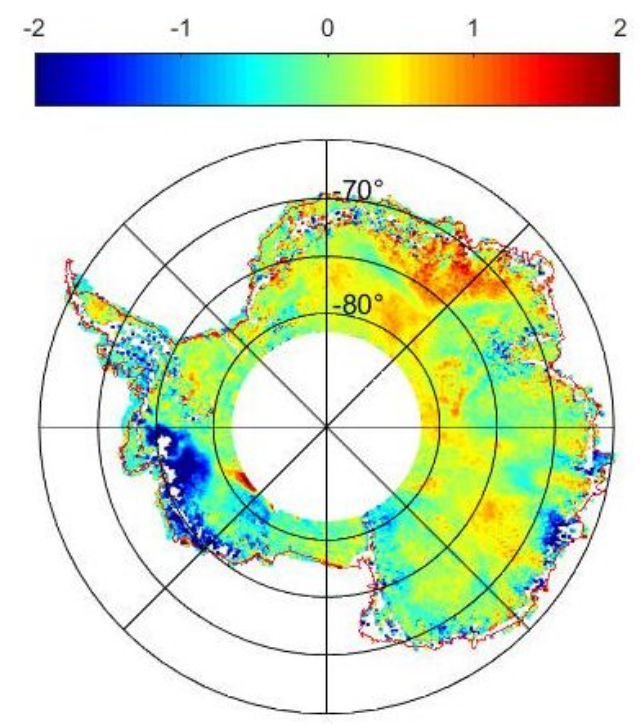

Figure 22. Difference (in $\mathrm{m}$ ) between $\mathrm{Ka}$ and Ku-band height from the Envisat and SARAL/AltiKa altimeter over Antarctica. Due to the difference of penetration, in the central part, the Ku-band elevation is indeed below the Ka one. Near the coast, the smaller antenna aperture of Ka-band yields to a smaller slope error. In the West Antarctica sector, the negative pattern is due to the decrease of surface topography between the time of Envisat and of SARAL/AltiKa . 
The characteristics of SARAL/AltiKa ensures a temporal stability of height retrieval that allows to obtain elevation trends with a good confidence. We well map the impressive loss of outlet glaciers of the West part of the continent. We are able to describe the large digging of Pine Island glacier from ERS-1 to Envisat and now its large enlargement during SARAL/AltiKa period [2].

\subsection{Icebergs}

Altimeters are powerful tools to study icebergs, either small ( $<3 \mathrm{~km}$ in length) or large (length $>16 \mathrm{~km}$ ). Indeed, [38] demonstrated that small icebergs can produce a detectable signature in high resolution altimeter waveforms, at least in sea ice free ocean. Their method enables to detect, and to estimate the iceberg area from these signatures. The constraints on the method limit the detection to icebergs between $0.1 \mathrm{~km}^{2}$ and $8 \mathrm{~km}^{2}$. Nine satellite altimetry missions have already been processed to produce a 1992-present database of small iceberg location, area, volume and mean backscatter $([39,40])$. Monthly mean probability of presence, area and volume of ice over a regular polar $\left(100 \times 100 \mathrm{~km}^{2}\right)$ or geographical $\left(1^{\circ} \times 2^{\circ}\right)$ grid are also available and are distributed on the Centre ERS d'Archivage et de Traitement (CERSAT) website. The archive of SARAL/Altika has of course been processed and is part of the database. Comparison of the detection results from classical $\mathrm{Ku}$ band altimeters (such as Jason-series) showed that the SARAL/AltiKa higher waveform frequency of $40 \mathrm{~Hz}$ as well as the smaller footprint significantly improves the detection of the smallest icebergs [40] and that SARAL/AltiKa could be used as a reference to inter-calibrate the volume of ice estimates from the different sensors.

Altimeter can also be used to measure the freeboard elevation profile of large icebergs [41,42]. Combining iceberg tracks from the National Ice Center (NIC) and the archives of three Ku band altimeters, Jason-1, Jason-2 and Envisat, a database of the daily position, free-board profile, length, width, area and volume of large icebergs covering the 2002-2012 period is presented in [42]. Compared to Ku-band altimeters, the SARAL/AltiKa smaller footprint and higher waveform rate allows a better estimation of the elevation and backscatter profiles over icebergs. Figures 23 and 24 compare Jason-2 and SARAL/AltiKa data over a large iceberg (C16) detected in the Weddell Sea. They present MODIS images of the iceberg (Figures 23 and 24a) as well as the raw altimeter waveforms (Figures 23 and 24b) and the waveforms repositioned using the altimeter tracker position to better show the iceberg signature (Figures 23 and 24c). The iceberg elevation profile is estimated using a simple tracker based on the detection for each waveform of the first occurrence (bin) of a power gradient larger than a given threshold [42]. As the altimeter approaches the iceberg from the north near $65.3^{\circ} \mathrm{S}$, the tracker starts to move up (Figures 23 and 24c,d) mitigating the sea and iceberg surfaces elevation as it can be seen. As the tracker is not locked on the iceberg surface, the strong echo from the iceberg starts to appear in the first gate of the waveforms, and then moves toward the nominal track point (0), while the echo from the sea surface moves away from zero (Figures 23 and 24b). The length over which the altimeter footprint contains both ocean and iceberg depends on the angle between the ground track and the iceberg, and on the footprint size. SARAL/AltiKa smaller footprint $(5.6 \mathrm{~km}$ vs. $8.6 \mathrm{~km}$ for the last range bin) significantly reduces the transition length (see Figures 23 and 24d) by almost a factor 2 compared to Jason-2, especially for slanted angles. The $40 \mathrm{~Hz}$ waveform rate also combined with the smaller footprint lead to a more rapid detection by the tracker of the elevation transition between ocean and iceberg and iceberg and ocean. The detection of the iceberg edges although not perfect for slanted angles is significantly better than that of $\mathrm{Ku}$ band altimeters. Furthermore, as SARAL/AltiKa footprint is smaller, the probability that a waveform is not contaminated by ocean, i.e., that the elevation and backscatter measurements are more precise, is higher than that for Ku band altimeters. This can be clearly seen in Figures 23 and 24; whereas the SARAL/AltiKa backscatter clearly shows a decrease associated to the iceberg slope (Figure 23d) and sharp jumps between ocean and icebergs, it is difficult to identify the transition between iceberg and ocean for Jason-2. 


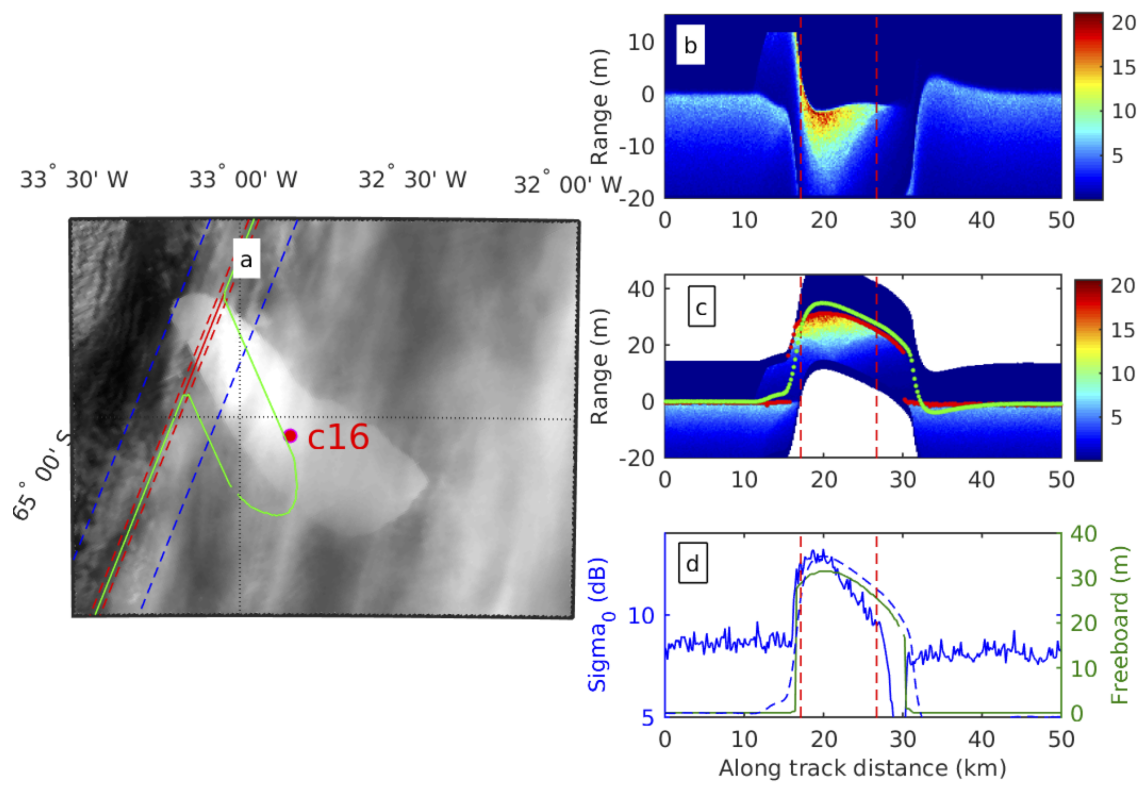

Figure 23. (a) MODIS image on 17 March 2013 17:34 UT and SARAL/AltiKa descending pass 102 Cycle 1 (17 March 2013 18:19UT). The red and blue dashed lines indicate the width of the first and last range bins, respectively, and the green line the elevation profile. (b) SARAL/AltiKa waveforms over C16. The dashed red lines indicate the iceberg limits from MODIS image. (c) Re-tracked waveforms using the tracker position, the green line represents the tracker position and the red line the elevation profile using a dedicated re-tracker. (d) Re-tracked elevation profile (green line), tracker position (dashed green line) and measured backscatter (blue line).

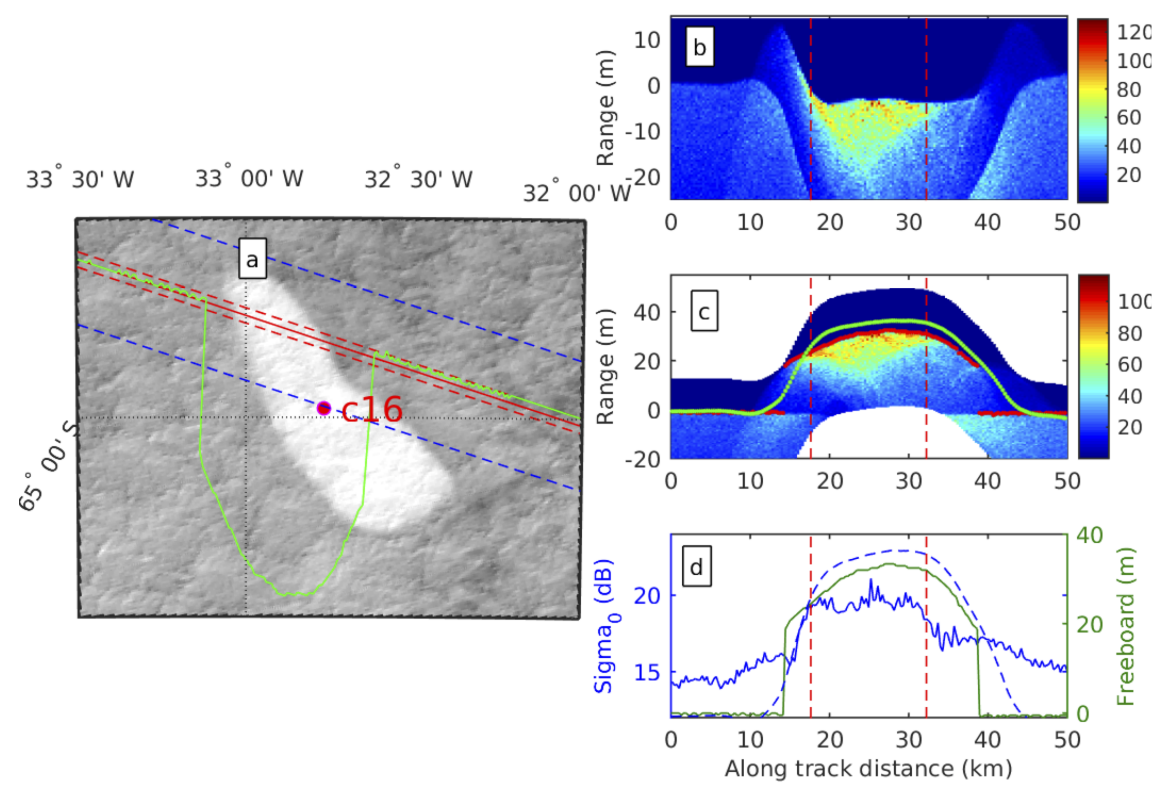

Figure 24. (a) MODIS image on 20 March 2013 16:45 UT and Jason-2 descending pass 180 Cycle 173 (20 March 2013 12:48UT). The red and blue dashed lines indicate the width of the fist range and last bins, respectively, and the green line the elevation profile. (b) Jason-2 waveforms over C16. The dashed red lines indicate the iceberg limits from MODIS image. (c) Re-tracked waveforms using the tracker position, the green line represents the tracker position and the red line the elevation profile using a dedicated re-tracker. (d) Re-tracked elevation profile (green line), tracker position (dashed green line) and measured backscatter (blue line). 


\subsection{Sea Ice}

Regarding sea ice surfaces, SARAL/AltiKa offers mainly two advantages relatively to conventional $\mathrm{Ku}$-band radar altimeters:

- First, its smaller footprint, higher vertical resolution $(\sim 30 \mathrm{~cm})$ and higher horizontal sampling $(\sim 180 \mathrm{~m})$ allow a better discrimination between ice floes and open sea ice fractures (generally referred to as leads), which strongly improves the measurement of sea level and freeboard height. These improvements are somehow counter-balanced by the technical issue of waveform saturation while the altimeter overflight surfaces with highly variable scattering. This effect tends to degrade the range estimation during the approach phase of specular surfaces like leads. However, the reactivity of the Attenuation Gain Controller can be easily corrected in future altimeter version.

- The second advantage of SARAL/AltiKa lies on its higher radar frequency: Unlike Ku-band radar altimeters, the Ka-band radar signal of AltiKa penetrates only part of the snowpack and possibly less than $3 \mathrm{~cm}$ [43]. The latter study uses this difference of penetration depth between $\mathrm{Ku}$ - and Ka-band altimeters to estimate a proxy of snow depth at the top of sea ice by combining SARAL/AltiKa (Ka-band) and CryoSat-2/SIRAL (Ku-band) (Figure 25). As the uncertainty related to the impact of snow depth on the freeboard-to-thickness conversion can be up to $100 \%$, this opportunity of measuring snow depth from Ka- and Ku-band radar altimetry represents a real breakthrough. In addition to the freeboard-to-thickness conversion, the snow depth measurement could be of hight interest for the quantification of energy, transfer between the atmosphere and the ocean as well as for the estimation of freshwater fluxes in the ocean.

The potential of combining Ka and Ku-band measurements to estimate snow depth at the top of sea ice is currently further investigated. In particular, the CryoVex airborne campaign carried, for the first time in March 2017, a Ka-band altimeter (Karen) in addition to the usual Ku-band altimeter (ASIRAS). The analysis of these highly accurate and colocated measurements will allow to provide more evidences on the interest of combining $\mathrm{Ka}$ and $\mathrm{Ku}$ band radar altimetry and could be a basis for the development of future polar altimetric missions.

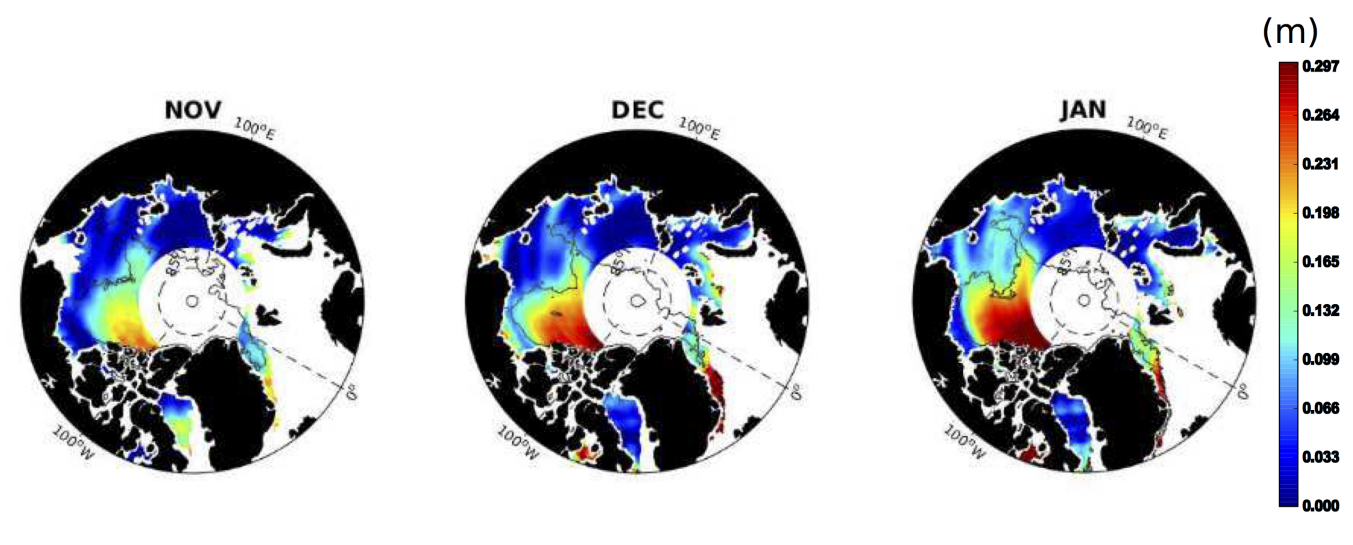

Figure 25. Maps of snow depth estimated from the combinaition of SARAL/AltiKa and CryoSat-2/SIRAL for November 2013, December 2013 and January 2014 [43].

\section{Geodesy}

Satellite altimetry has also become an effective remote sensing technique with important applications to geodesy [44]. Indeed, satellite altimetry has impact to geodesy by allowing mapping and monitoring a major part of the Earth surface and to make improvements on the measurements of the gravity field. The altimetric constellation with a number of successive and/or parallel missions with different orbit configuration and sampling characteristics are very supportive of geodetic applications. 
The case of SARAL/AltiKa in its SARAL-DP configuration is of particular interest in this regard, as it is covering the earth with a very fine resolution well suited.

\section{Ability to Find Uncharted Seamounts}

Seamounts-undersea mountains of volcanic origin-are obstacles to flow, sites of enhanced mixing, habitat for fish, and possible hazards to submarines. Small seamounts are more common than large ones. Wessel et al. [45] found that all seamounts 2000 meters tall and taller appeared to have been found by the satellite altimeters of that time, but suggested that there might be as many as one hundred thousand seamounts between 1000 and $2000 \mathrm{~m}$ tall that had escaped detection. Since only about eight percent of the ocean floor has been sounded to one nautical mile resolution [46], the discovery of new seamounts will come mainly from new satellite altimetry. However, small seamounts remain difficult to find because they create only small anomalies in sea level (Figure 26). Smith [47] showed that the AltiKa altimeter on SARAL/AltiKa has much better precision in sea level measurement than previous $\mathrm{Ku}$-band altimeters, and that this precision can be used to detect seamounts as small as $1 \mathrm{~km}$ tall. Marks [48] showed that a sea surface height profile made from the temporal median of SARAL/AltiKa repeat-track profiles can detect even smaller seamounts. It is now expected that SARAL's new geodetic mission will furnish data for finding many previously unknown seamounts. This will be a boon to scientists modelling ocean flow and mixing, to marine biologists and commercial fishermen, and perhaps also to navies that must navigate submarines.
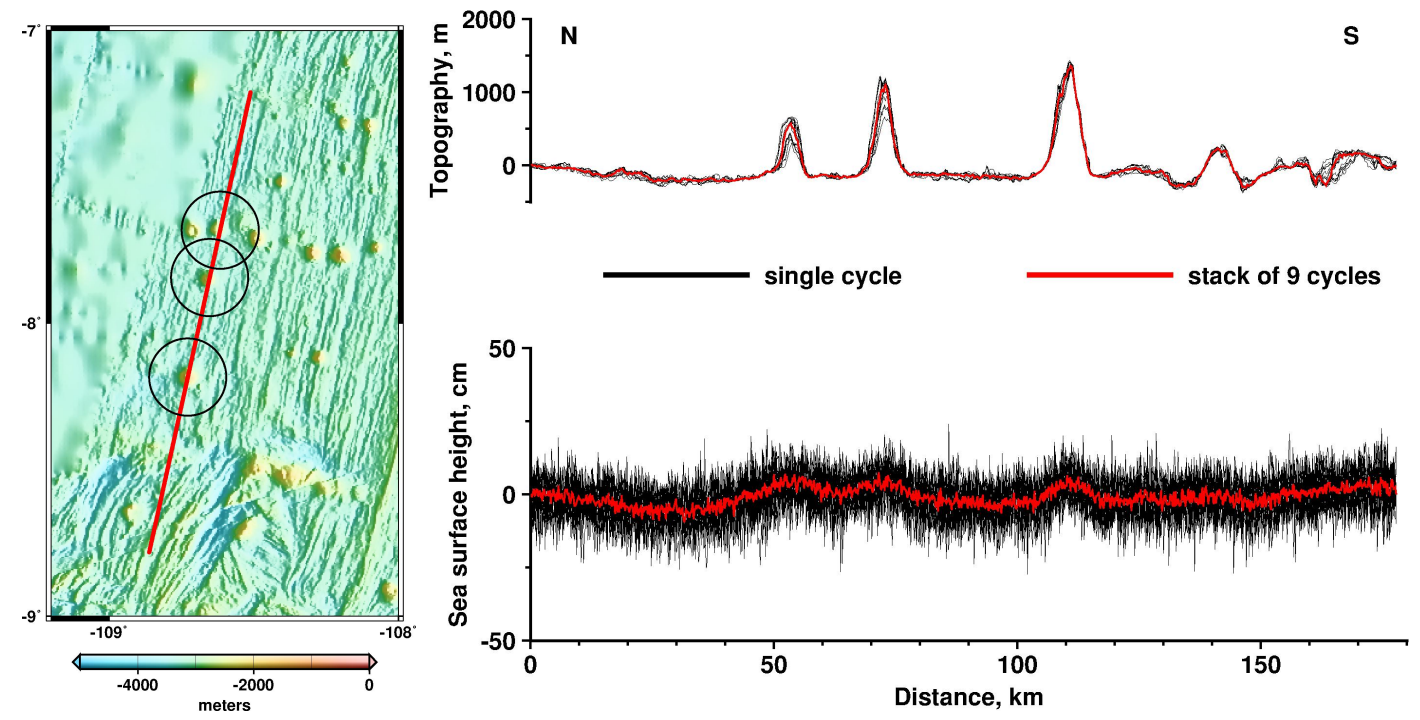

Figure 26. The red line shows the ground track of a SARAL/AltiKa repeat cycle (pass number 0396) over three small seamounts (in black circles). Seafloor topography is shown in the coloured image; the detailed portion is covered by a multi-beam echo sounder survey that confirms the position and height of the seamounts. Profiles along the red line in the previous image, showing: the sea floor topography under the satellite track (top); and the sea surface height anomaly (bottom). Black curves are individual results from each repeat cycle. The red curves are the median of all repeat cycles. The sea surface height anomaly produced by the seamounts is only 5 to $10 \mathrm{~cm}$ high, but is detectable, thanks to the better precision furnished by SARAL/AltiKa.

\section{Conclusions}

SARAL/AltiKa was launched on 25 February 2013. At the beginning, the SARAL/AltiKa mission was strongly motivated by a necessity by the research and operational oceanographic communities because of the need to fill the gap after the Envisat mission and before Jason-3 and Sentinel-3. Indeed, these objectives were completely fulfilled. However, the SARAL/AltiKa altimeter is also, and perhaps above all, the first oceanographic altimeter to use a high single frequency in Ka-band 
(35.75 GHz). A little less than five years after launch, the satellite and the instruments onboard are performing well although the control of the reaction wheels appeared to be impossible at some stage, end of 2015 and beginning of 2016, leading the leave of the exact 35 repeat orbit and a shift to the Drifting Orbit Phase. Note this change had no impact of the quality and the availability of the SARAL/AltiKa data but only on the time/space sampling. As of today, all components of the altimetric system (i.e. AltiKa itself) are working properly.

Calibration and validation investigations have shown that the quality of the data meets the expectations and initial mission requirements and this is still correct [4]. Since the launch, the quality of all products appears to be continuously in line with the mission requirements. A large number of scientific investigations have been undertaken and SARAL/AltiKa has become a fully-fledged member of the altimetric constellation.

The advantages/drawbacks of the Ka-band summarize as follows:

- The higher frequency (35.75 GHz, to be compared to $13.5 \mathrm{GHz}$ on Jason-2) leads to a smaller footprint ( $8 \mathrm{~km}$ diameter, to be compared to $20 \mathrm{~km}$ on Jason- 2 and to $15 \mathrm{~km}$ for Envisat) and thus a better horizontal resolution.

- Ka-band allows to use a larger bandwidth (480 MHz to be compared to $320 \mathrm{MHz}$ on Jason-2). This $480 \mathrm{MHz}$ bandwidth provides a high vertical resolution $(0.3 \mathrm{~m})$ which is better with respect to other altimeters.

- The higher Pulse Repetition Frequency (4 kHz to be compared to $2 \mathrm{kHz}$ on Jason-2) permits a decorrelation time of sea echoes at Ka-band shorter than at Ku-band, then allowing a better along-track sampling. This makes possible to increase significantly the number of independent echoes per second compared with Ku-band altimeters.

- Ka-band is much less affected by the ionosphere than one operating at Ku-band. This low ionospheric attenuation can even be considered as negligible, except for some exceptional ionospheric situations. It discards the need for a dual-frequency altimeter.

- Ka-band provides a better estimation of sea surface roughness than at Ku-band. The $8 \mathrm{~mm}$ wavelength in Ka-band is better suited to describing the slopes of small facets on the sea surface (capillary waves, etc.) and gives a more accurate measurement of the backscatter coefficient over calm or moderate seas, thus leading to a noise reduction of a factor of two compared to Jason-class altimeters for wave heights greater than $1 \mathrm{~m}$. Moreover, the specificities of the Ka-band backscatter coefficient offer unique contributions in fields that where not foreseen (snow/ice morphology and its temporal variability (Section 4), soil moisture [4], etc.).

- With Ka-band, there is a lower radar penetration of snow and ice: penetration of snowpack is less than $3 \mathrm{~cm}$ for snow on sea ice and $1 \mathrm{~m}$ for continental ice, around ten times less than for Ku-band. The altimetric observation and height restitution thus correspond to a thin subsurface layer.

- A possible drawback of Ka-band was that the attenuation due to water or water vapour in the troposphere might affect Ka-band pulses in case of rain and increase significantlly the rate of missing data for strong rain rates. In fact, this was not found to be true in practice and rain had little influence on data availability and quality.

Regarding the oceans, SARAL/AltiKa provides an improved resolution of the SSH signal in particular of the mesoscales. Regarding the along-track SSH spatial resolution SARAL/AltiKa provides resolution down to $40-50 \mathrm{~km}$ wavelengths, whereas Jason and Envisat altimeters resolve down to $70-80 \mathrm{~km}$ wavelengths. Sentinel-3 SAR is still being analyzed, but it is suggested to also be resolved to $30-50 \mathrm{~km}$ wavelengths. The coastal oceans, directly benefit of the better discrimination in transition zones as well as this improved resolution of the measurements. Progress has been made in reducing the altimeter footprints and noise to approach closer to the coast, but also in processing algorithms, corrections, and products for coastal applications. The improved coastal altimeter data and their derived sea level and wind-wave data are being integrated into coastal observing systems. These data provide essential monitoring for both research and operational applications, in these coastal regions where in situ measurements are sparse. 
Regarding inland waters, SARAL/AltiKa definitely improves the quality of hydrology products derived from satellite altimetry. Especially for water level time series over lakes and rivers it was shown that SARAL/AltiKa dramatically improved the quality due to its smaller footprint and its higher pulse repetition frequency. In particular, SARAL/AltiKa allows the access to smaller rivers and lakes that were not "visible" with standard altimeters. The impact of clouds or precipitation on the resulting water levels exists, but is not so strong that the data cannot be used for reliable and accurate estimation of water level time series. With regard to Envisat for example, the waveform disruption for SARAL/AltiKa for height estimation is better with SARAL/AltiKa. SARAL/AltiKa has the potential to provide better water level heights until $6 \mathrm{~km}$ near to the lake shore than Envisat. In addition, SARAL/AltiKa provides more homogenous water level heights over rivers than Envisat.

Regarding ice, the lesser radar penetration of snow is beneficial for various types of measurements. The difference between $\mathrm{Ka}$ and $\mathrm{Ku}$-band height provides a good proxy of snow depth above sea ice that is a limitation to estimate ice thickness and is a climate indicator. Above ice sheet it ensures a mean to better constrain the waveform models and invert snowpack characteristics. Combined with a better spatial resolution, Ka-band in SAR mode for instance, would therefore allow closer monitoring of sea and continental ice. As for inland waters applications, ice applications gave evidence of the key importance of continuous observations along the same repeat orbit, as was possible with ERS-2, Envisat and SARAL/AltiKa (during the nominal phase).

Regarding geodesy, it appears that AltiKa is an excellent altimeter for resolving short-wavelength geoid anomalies. SARAL/AltiKa is now in its Drifting Phase, the dataset that would result would be a boon to marine geophysics, bathymetric estimation, and seamount mapping. Seamount size-frequency distribution models suggest that there may be as many as 105 seamounts between 1 and $2 \mathrm{~km}$ in height that are uncharted and were not detected by previous Ku-band altimeters. During its Drifting Phase, SARAL/AltiKa will surely find some of these.

A general observation is that the implementation of SARAL/AltiKa data into operational systems has been extremely easy both into operational oceanography centres for the SSH signal and into meteorological centres for the SWH in particular. It has also been the case for building databases of various levels of sophistication, for example for AVISO that integrates SARAL/AltiKa data as well as other altimeter data.

SARAL/AltiKa is in many respects a prototype of the altimetry of the future. SARAL/AltiKa represents the beginning of a new class of altimeters operating at Ka-band frequency with a small footprint and high pulse rate. The Ka-band is envisioned for several new altimetric satellite projects (i.e. AltiCryo from CNES, CryoSat-3 and SKIM from ESA) and the chosen band for the upcoming SWOT. It even opens more than previously the doors of interdisciplinarity. Indeed, the extended capabilities that are offered by the Ka-band allow to open even more widely some new frontiers of altimetry such as coastal oceanography, cryosphere, hydrology, beyond the traditional scope of the open ocean investigations. Ka-band altimetry, with SARAL/AltiKa as the today's most emblematic declination, can be seen also as a step towards improved resolution altimetry and a preparation for the NASA-CNES SWOT mission project and the KaRIN instrument (Ka-band Radar INterferometer).

Acknowledgments: The SARAL/AltiKa mission is an achievement of a very fruitful cooperation between ISRO and CNES. The contribution of EUMETSAT to data distribution is also strongly appreciated. We acknowledge the support of all the Investigators, PIs and Co-Is, of the SARAL/AltiKa Mission. Most of the studies performed by the French authors have been conducted and financed thanks to Centre National d'Etudes Spatiales (CNES), Centre National de la Recherche Scientifique (CNRS), and French Ministry of Research. The manuscript contents are solely the opinions of the authors and do not constitute a statement of policy, decision, or position on behalf of NOAA or the U. S. Government.

Author Contributions: Jacques Verron and Pascal Bonnefond coordinated the whole paper. For the ocean, Rosemary Morrow, Oscar Vergara, Marie-Isabelle Pujol and Gérald Dibarboure brought their contribution to Section 2.1; Florence Birol, Fatma Jebri and Ananda Pascual to Section 2.2; Yannice Faugère, Marie-Isabelle Pujol, Elisabeth Rémy, Mathieu Hamon and Lofti Aouf to Section 2.3; and Suchandra A. Bhowmick and Raj Kumar to Section 2.4. On inland waters, P. K. Gupta, A. K. Dubey, Taina Conchy and Stéphane Calmant brought their contribution to Section 3.1.1; and Jean-François Crétaux to Section 3.2. On ice, Frédérique Rémy brought her 
contribution to Section 4.1; Jean Tournadre to Section 4.2 ; and Kevin Guerreiro to Section 4.3. On geodesy, Walter H. F. Smith contributed to Section 5.

Conflicts of Interest: The authors declare no conflict of interest.

\section{References}

1. Vincent, P.; Steunou, N.; Caubet, E.; Phalippou, L.; Rey, L.; Thouvenot, E.; Verron, J. AltiKa: A Ka-band altimetry payload and system for operational altimetry during the GMES period. Sensors 2006, 6, 208-234.

2. Verron, J.; Sengenes, P.; Lambin, J.; Noubel, J.; Steunou, N.; Guillot, A.; Picot, N.; Coutin-Faye, S.; Gairola, R.; Raghava Murthy, D.V.A.; et al. The SARAL/AltiKa altimetry satellite mission. Mar. Geodesy 2015, 38, 2-21.

3. The SARAL/AltiKa Satellite Altimetry Mission. Mar. Geodesy 2015, 38. Available online: http://www. tandfonline.com/toc/umgd20/38/sup1 (accessed on 12 January 2018)

4. Bonnefond, P.; Verron, J.; Aublanc, J.; Babu, K.N.; Bergé-Nguyen, M.; Cancet, M.; Chaudhary, A.; Crétaux, J.F.; Frappart, F.; Haines, B.J.; et al. The benefits of the Ka-band as evidenced from the SARAL/AltiKa altimetric mission: Quality assessment and specificities of AltiKa data. Remote Sens. 2018, 10, 83, doi:10.3390/rs10010083.

5. Dufau, C.; Orsztynowicz, M.; Dibarboure, G.; Morrow, R.; Le Traon, P.Y. Mesoscale Resolution Capability of altimetry: Present \& future. J. Geophys. Res. Oceans 2016, 121, 4910-4927.

6. Ablain, M.; Raynal, M.; Lievin, M.; Thibaut, P.; Dibarboure, G.; Picot, N. Improving altimeter sea level calculation at small ocean scales. In Proceedings of the 2016 Ocean Surface Topography Science Team (OSTST) Meeting, La Rochelle, France, 31 October-1 November 2016.

7. Morrow, R.; Carret, A.; Birol, F.; Nino, F.; Valladeau, G.; Boy, F.; Bachelier, C.; Zakardjian, B. Observability of fine-scale ocean dynamics in the Northwest Mediterranean Sea. Ocean Sci. 2017, 13, 13-29.

8. Dibarboure, G.; Pujol. M.I.; Briol, F.; Le Traon, P.Y.; Larnicol, G.; Picot, N.; Mertz, F.; Ablain, M. Jason-2 in DUACS: Updated System Description, First Tandem Results and Impact on Processing and Products. Mar. Geodesy 2011, 34, 214-241.

9. Pujol, M.-I.; Schaeffer, P.; Faugére, Y.; Raynal, M.; Dibarboure, G.; Picot, N. Gauging the improvement of recent mean sea surface models: A new approach for identifying and quantifying their errors. J. Geophys. Res. 2017, submitted.

10. Jebri, F.; Birol, F.; Zakardjian, B.; Bouffard, J.; Sammari, C. Exploiting coastal altimetry to improve the surface circulation scheme over the central Mediterranean Sea. J. Geophys. Res. Ocean. 2016, 121, 4888-4909.

11. Sorgente, R.; Olita, A.; Oddo, P.; Fazioli, L.; Ribotti, A. Numerical simulation and decomposition of kinetic en e.g., in the Central Mediterranean: Insight on mesoscale circulation and en e.g., conversion. Ocean Sci. 2011, 7, 503-519.

12. Rubio, A.; Mader, J.; Corgnati, L.; Mantovani, C.; Griffa, A.; Novellino, A.; Quentin, C.; Wyatt, L.; Schulz-Stellenfleth, J.; Horstmann, J.; et al. HF Radar Activity in European Coastal Seas: Next Steps toward a Pan-European HF Radar Network. Front. Mar. Sci. 2017, 4, 8.

13. Pascual, A.; Lana, A.; Troupin, C.; Ruiz, S.; Faugère, Y.; Escudier, R. Assessing SARAL/AltiKa delayed-time data in the coastal zone: Comparisons with HFR observations. Mar. Geodesy 2015, 38, 260-276.

14. Rio, M.-H.; Pascual, A.; Poulain, P.-M.; Menna, M.; Barcelò-Llull, B.; Tintoré, J. Computation of a new mean dynamic topography for the Mediterranean Sea from model outputs, altimeter measurements and oceanographic in-situ data. Ocean Sci. 2014, 10, 731-744.

15. Pujol, M.I.; Faugère, Y.; Taburet, G.; Dupuy, S.; Pelloquin, C.; Ablain, M.; Picot, N. DUACS DT2014: The new multi-mission altimeter dataset reprocessed over 20 years. Ocean Sci. 2016, 12, 1067-1090.

16. Le Traon, P.Y.; Antoine, D.; Bentamy, A.; Bonekamp, H.; Breivik, L.A.; Chapron, B.; Corlett, G.; Dibarboure, G.; Digiacomo, P.; Donlon, C.; et al. Use of satellite observations for operational oceanography: Recent achievements and future prospects. J. Oper. Ocean. 2015, 8 (Suppl. 1), 12-27.

17. Desroziers, G.; Berre, L.; Chapnik, B.; Poli, P. Diagnosis of observation, background and analysis-error statistics in observation space. Quart. J. R. Meteorol. Soc. 2005, 131, 3385-3396.

18. Calmant, S.; Seyler, F. Continental surface waters from satellite altimetry. Géosciences 2006, 338, 1113-1122.

19. Crétaux, J.F.; Birkett, C. Lake studies from satellite radar altimetry. Comptes Rendus Geosci. 2006, 338, $1098-1112$.

20. Crétaux, J.-F.; Abarca Del Rio, R.; Berge-Nguyen, M.; Arsen, A.; Drolon, V.; Clos, G.; Maisongrande, P. Lake volume monitoring from Space. Surv. Geophys. 2016, 37, 269-305. 
21. Alsdorf, D.; Beighley, E.; Laraque, A.; Lee, H.; Tshimanga, R.; O’Loughlin, F.; Dinga, B.; Moukandi, G.; Spencer, R.G. Opportunities for hydrologica research in the Congo basin. Rev. Geophys. 2016, 54, 378-409.

22. Laraque, A.; Bellanger, M.; Adèle, G.; Guebanda, S.; Gulemvuga, G.; Pandi, A.; Paturel, J.E.; Robert, A.; Tathy, J.P.; Yambele, A. Recent evolution of Congo, Oubangui and Sangha Rivers flows. Acad. R. Sci. Belgique Geogr. Ecol. Trop. 2013, 37, 93-100.

23. Silva, J.; Calmant, S.; Seyler, F.; Medeiros Moreira, D.; Oliveira, D.; Monteiro, A. Radar Altimetry aids Managing gauge networks. Water Resour. Manag. 2014, 28, 587-603.

24. Dubey, A.K.; Gupta, P.; Dutta, S.; Pratap Sing, R. Water Level retrieval Using SARAL/AltiKa Observations in the braided Brahmapoutra River, Eastern India. Mar. Geodesy 2015, 38, 549-567.

25. Frappart, F.; Papa, F.; Marieu, V.; Malbeteau, Y.; Jordy, F.; Calmant, S.; Durand, F.; Bala, S. Preliminary assessment of SARAL/AltiKa observations over the Ganges-Brahmaputra and Irrawaddy Rivers. Mar. Geodesy 2015, 38, 568-580.

26. Schwatke, C.; Dettmering, D.; Borgens, E.; Bosch, W. Potential of SARAL/Altika for Inland Water Application. Mar. Geodesy 2015, 38, 626-643.

27. Frappart, F.; Calmant, S.; Cauhopé, M.; Seyler, F.; Cazenave, A. Results of Envisat RA-2 Derived levels Validation over the Amazon basin. Remote Sens. Environ. 2006, 100, 252-264.

28. Silva, J.; Calmant, S.; Rotuono Filho, O.; Seyler, F.; Cochonneau, G.; Roux, E.; Mansour, J.W. Water Levels in the Amazon basin derived from the ERS-2 and Envisat Radar Altimetry Missions. Remote Sens. Environ. 2010, 114, 2160-2181.

29. Paris, A.; Santos da Silva, J.; Dias de Paiva, R.; Medeiros Moreira, D.; Calmant, S.; Collischonn, W.; Bonnet, M.-P.; Seyler, F. Global determination of rating curves in the Amazon basin. Water Resour. Res. 2016, 28, 3787-3814.

30. Wang, B.; Bao, Q.; Hoskins, B.; Wu, G.; Liu, Y. Tibetan Plateau warming and precipitation change in East Asia. Geophys. Res. Lett. 2008, 35, L14702.

31. Liu, J.; Wang, S.; Yu, S.; Yang, D.; Zhang, L. Climate warming and growth of high-elevation inland lakes on the Tibetan Plateau. Glob. Planet. Chang. 2009, 67, 209-217.

32. Lei, Y.; Yang, K.; Wang, B.; Sheng, Y.; Bird, B.W.; Zhang, G.; Tian, L. Response of inland lake dynamics over the Tibetan Plateau to climate change. Clim. Chang. 2014, 125, 281-290.

33. Phan, V.H.; Lindenb, R.C.; Menenti, M. Geometric dependency of Tibetan lakes on glacial runoff. Hydrol. Earth Syst. Sci. Discuss. 2013, 10, 729-768.

34. Arsen, A.; Cretaux, J.-F.; Abarca-Del-Rio, R. Use of SARAL/AltiKa over mountainous lakes, intercomparison with Envisat mission. J. Adv. Space Res. 2015, 38, 534-548.

35. Remy, F.; Flament, T.; Michel, A.; Verron, J. Ice sheet survey over Antarctica with satellite altimetry: ERS-2, Envisat, SARAL/AltiKa, the key importance of continuous observations along the same repeat orbit. Int. J. Remote Sens. 2014, 35, 5497-5512.

36. Kouraev, A.; Zakharova, E.; Remy, F. Study of Lake Baikal ice cover from radar altimetry and in situ observations. Mar. Geodesy 2015, 38, 477-486

37. Rémy, F.; Flament, T.; Michel, A.; Blumstein, D. Envisat and SARAL/AltiKa observations of the Antarctic ice sheet: A comparison between the Ku-band and the Ka-band. Mar. Geodesy 2015, 38, 510-521.

38. Tournadre, J. Signature of Lighthouses, Ships, and Small Islands in Altimeter Waveforms. J. Atmos. Ocean. Tech. 2007, 24, 1143-1149.

39. Tournadre, J.; Girard-Ardhuin, F.; Legresy, B. Antarctic iceb e.g., distributions, 2002-2010. J. Geophys. Res. 2012, 117, C05004.

40. Tournadre, J.; Bouhier, N.; Girard-Ardhuin, F.; Remy, F. Antarctic iceb e.g., distributions $1992-2014$. J. Geophys. Res. 2016, 121, 327-349.

41. McIntyre, N.F.; Cudlip, W. Observation of a giant Antarctic tabular iceberg by satellite radar altimetry. Polar Rec. 1987, 145, 458-462

42. Tournadre, J.; Bouhier, N.; Girard-Ardhuin, F.; Remy, F. Large iceb e.g., characteristics from altimeter waveforms analysis. J. Geophys. Res. 2015, 120, 1954-1974.

43. Guerreiro, K.; Fleury, S.; Zakharova, E.; Rémy, F.; Kouraev, A. Potential for estimation of snow depth on Arctic sea ice from CryoSat-2 and SARAL/AltiKa missions. Remote Sens. Environ. 2016, 186, 339-349.

44. Smith, W.H.F.; Barale, V.; Gower, J.; Alberotanza, L. The Marine Geoid and Satellite Altimetry. In Oceanography from Space; Springer: Dordrecht, The Netherlands, 2010. 
45. Wessel, P. Global distribution of seamounts inferred from gridded Geosat/ERS-1 altimetry. J. Geophys. Res. 2001, 109, 19431-19441.

46. Wessel, P.; Chandler, M.T. The spatial and temporal distribution of marine geophysical surveys. Acta Geophys. 2011, 59, 55-71.

47. Smith, W.H.F. The Resolution of Seamount Geoid Anomalies Achieved by the SARAL/AltiKa and Envisat RA2 Satellite Radar Altimeters. Mar. Geodesy 2015, 38, 644-671.

48. Marks, K.M.; Smith, W.H.F. Detecting small seamounts in AltiKa repeat cycle data. Mar. Geophys. Res. 2016, 37, 349-359.

(C) 2018 by the authors. Licensee MDPI, Basel, Switzerland. This article is an open access article distributed under the terms and conditions of the Creative Commons Attribution (CC BY) license (http:/ / creativecommons.org/licenses/by/4.0/). 